\title{
Effect of Local Metakaolin Developed from Natural Material Soorh and Coal Bottom Ash on Fresh, Hardened Properties and Embodied Carbon of Self- Compacting Concrete
}

\section{Manthar Ali Keerio}

Quaid-e-Awam University of Engineering Science and Technology

Abdullah Saand

Quaid-e-Awam University of Engineering Science and Technology

Aneel Kumar

Mehran University of Engineering and Technology

Naraindas Bheel ( $\sim$ naraindas_20001014@utp.edu.my )

Universiti Teknologi Petronas: Universiti Teknologi PETRONAS https://orcid.org/0000-0003-1691-9735

Karm Ali

Quaid-e-Awam University of Engineering Science and Technology

\section{Research Article}

Keywords: Metakaolin, Cement substitute material, Coal bottom ash, sand substitute ingredient, SCC, Fresh and hardened properties of SSC, Embodied carbon, Sustainability.

Posted Date: April 28th, 2021

DOl: https://doi.org/10.21203/rs.3.rs-427666/v1

License: (c) (i) This work is licensed under a Creative Commons Attribution 4.0 International License.

Read Full License 


\section{Abstract}

The carbon dioxide emissions from Portland cement production have increased significantly and Portland cement is the main binder used in self-compacting concrete, so there is an urgent need to find environmental friendly materials as alternative resources. In most developing countries, the availability of huge amounts of agricultural waste has paved the way for studying how these materials can be processed into self-compacting concrete as binder and aggregates compositions. Therefore, this experimental program was carried out to study the properties of self-compacting concrete (SCC) made with local metakaolin, coal bottom ash separately and combined. Total 25 mixes were prepared with four mixes as $5,10,15$ and $20 \%$ replacement of cement with metakaolin, four mixes as $10,20,30$ and $40 \%$ of coal bottom ash as partial replacement of fine aggregates separately and 16 mixes prepared combined with metakaolin and coal bottom ash. The fresh properties were explored by slump flow, $T_{50}$ flow, Vfunnel, L-box, J-Ring sieve segregation test. Moreover, the hardened properties of concrete were performed for compressive, splitting tensile and flexural strength and permeability of SCC mixtures. Fresh concrete test results show that even if no viscosity modifier is required, satisfactory fresh concrete properties of SCC can be obtained by replacing the fine aggregate with coal bottom ash content. At $15 \%$ replacement of cement with local metakaolin is optimum and gave better results as compared to control SCC. At $30 \%$ replacement of fine aggregate is optimum and gave better results as compared to control SCC. In the combined mix $10 \%$ replacement of cement with metakaolin combined with $30 \%$ replacement of fine aggregate with coal bottom ash is optimum and gave better results as compared to control SCC.

\section{Introduction}

Self-compacting concrete (SCC) is a highly workable concrete that can be spread over the packed reinforcement bars, seals overall corners of the formwork and attains compacted situation under its selfweight. Hence, there is no any vibrator is used for the compaction of concrete. To accomplish such conduct, the principle necessities of fresh properties of SCC are filling capacity, passing capacity and more segregation obstruction. The initial two assets can be accomplished by utilizing a chemical admixture (such as super plasticizer). To protect the cohesion of the SCC mixture, an enormous amount of supplementary cementing material (SCM) and viscosity-modifying admixture (VMA) is needed (EFNARC, 2005).

The construction industry is increasingly using the concepts of sustainability and durability. Cement is the most frequently utilized building ingredient in the construction engineering. It is a vitality comprehensive constituent and liable for high content of $\mathrm{CO}_{2}$ discharge. Hendricks et al detailed that the measure of $\mathrm{CO}_{2}$ discharges from cement production relies upon the manufacturing technology, procedure, clinker or cement proportion and fuel utilized. It presumed that the utilization of alternative fossil fuels and mixed cement may diminish $\mathrm{CO}_{2}$ releases by $20 \%$ to $40 \%$ and $20 \%$ correspondingly (Hendriks et al., 2004). Moreover, Hwang et al estimated the consumption of lime stone, electrical energy and fossil fuels to create one ton of OPC ranges from 1.19 tons to 1.47 tons, from $96.30 \mathrm{kWh}$ to 119.60 
kWh and $68.10 \mathrm{~kg}$ to $97.30 \mathrm{~kg}$ respectively (Hwang et al., 2015). The use of augmented energy, alternate raw constituents and decrease amounts of cement clinker will reduce $\mathrm{CO}_{2}$ emanations from the cement manufacturing (Damtoft et al., 2008). The use of pozzolanic ingredients increases the concrete durability and reduces $\mathrm{CO}_{2}$ emissions, since robust constructions structure want less repair and preservation, so it can also extend the life of the structure (Guneyisi et al., 2008). The use of volcanic ash is a trend that is attracting more and more attention, as well as increasing awareness of people about ecological protection and sustainable construction (Papadakis and Tsimas, 2002). Therefore, in the long term, there are good reasons to expand the use of any by-products or pozzolanic materials to partially replace cement in mortar and concrete. It is generally believed that volcanic ash significantly improves the resistance to chloride ions through a combination of chloride ions and pour filling (Rafik et al., 2010). The addition of pozzolanic materials to SCCs can improve strength, durability, lower costs and avoid side effects caused by improper compaction (Eva et al., 2011).

The durability of the pozzolanic concrete is improved owing to the pozzolanic response of different mixes existing in the concrete throughout the hydration cycle (Poon et al., 2001). The most usually utilized pozzolanic constituents are fly ash, silica fume, MK and rice husk ash. However, the calcium hydroxide $(\mathrm{CH})$ and calcium silicate hydrate $(\mathrm{C}-\mathrm{S}-\mathrm{H})$ are framed during the hydration of OPC in concrete. Besides, the calcium hydroxide is the greatest solvent hydration item, and it is a poor connection in concrete and cement in terms of durability perspective. Thus, the concrete is showing to water, the calcium hydroxide would disintegrate, expanding the permeability and in this manner, the production of concrete is more susceptible due to leaching and chemical attack. However, the pozzolanic MK reaction will form other cemented $\mathrm{C}-\mathrm{H}-\mathrm{H}$ gels and crystalline products, including calcium aluminate hydrate and aluminosilicate hydrate (C2ASH8, C4AH13, and C3AH6). These products of volcanic ash contribute to the narrowing of common pores (Badogiannis and Tsivilis, 2009). Wild et al., (1996) reported that the improved pore system makes the concrete denser, making it much more difficult to transport water and other corrosive chemicals, thereby reducing the diffusion frequency of injurious ions. Huang et al., (2015) assessed carbon dioxide emissions from cement production. Ordinary Portland cement is producing carbon dioxide by calcining limestone and silica reaction at temperatures below $1500^{\circ} \mathrm{C}$.

In this regard, it is conveyed that the utilization of MK in concrete makes it possible to improve the compressive strength of the mixture, particularly in the early stages of hydration. Kim et al., (2007) was stated that the strength of the concrete was measured using a Korean MK and it was recommended that a 10\% MK replacement would be a suitable replacement. In terms of durability, the literature has reported a positive effect of MK. Recently Shekarchi et al., (2010) states that when the amount of replacement MK was $15 \%$, concrete transport performance, recorded in terms of water permeability, gas permeability, water absorption, resistivity and ion diffusion rate, increased by $50 \%, 37 \%, 28 \% .450 \%$ and $47 \%$ correspondingly. Researchers have reported an optimistic influence of adding MK on the corrosion resistance of samples (Parande et al., 2008; Batis et al., 2005). For example, Batis et al., (2005) showed that the use of MK, regardless of whether it is used as a substitute for sand or cement, can improve the corrosion performance of mortar samples. 
The increase in the use of concrete has led to an increase in cement volumes and a gradual increase in demand for fine aggregates, which negatively affected the environment. In terms of reducing environmental pollution, the use of industrial waste may be a suitable solution for achieving sustainable development and solving the growing problem of carbon dioxide $\left(\mathrm{CO}_{2}\right)$ invention (Mangi et al., 2018). The $\mathrm{CBA}$ is measured as a green and ecologically friendly construction substantial that can reduce the cement content in concrete production. It is a waste ingredient which has introduced by the Construction Industry Development Board (CIDB) for the use of recycled materials in concrete production (Dwikojuliardi, 2015). Moreover, the CBA is formed by burning coal in thermal power plants and is measured the main waste of fly ash (FA). The CBA contains pozzolanic properties due to the existence of silicon oxide $\left(\mathrm{SiO}_{2}\right)$, aluminum oxide $\left(\mathrm{Al}_{2} \mathrm{O}_{3}\right)$ and iron oxide $\left(\mathrm{Fe}_{2} \mathrm{O}_{3}\right)$. During cement hydration, calcium hydroxide reacts with CBA to form additional calcium aluminate hydrate (CAH) and calcium silicate hydrate (CSH). Cheriaf et al., (1999) was argued that proper grinding can develop the pozzolanic activity of CBA, and six hours of grinding CBA can increase the strength activity index by $27 \%$ after 28 days. Hence, in concrete, it is partially replaced by fine aggregate and cement.

The use of $\mathrm{CBA}$ in the construction industry is one of the best possible options for reducing the environmental problems caused by lack of discharge sources and increased CBA productivity. Overall, India produces about 105 million tons of CBA per annum from various thermal power plants, which generate $68 \%$ of the country's electricity. Because CBA has the same particle size distribution and additional pozzolanic properties as NFA, CBA is promoting its use in the current and future construction industry (Lauritzen, n.d.; Yogesh and Rafat, 2014). Thus, the SCC has been studied many times and it is possible to replace NFA with CBA. In some studies (Abidin et al., 2014; Aswathy \& Mathews, 2015; Ibrahim et al., 2015; Jamaluddin et al., 2016; Ratchayut \& Somnuk, 2008), in the production of SCC, the bottom ash of coal was also mixed with cement additives such as FA and MK. But, the NFA was replaced by $10 \%$ $-30 \%$ of CBA along with FA and a water reducing agent were added simultaneously (Rafat et al., 2012; Rafat et al., 2012). It was observed that SCCs with CBA and FA could be designed to meet the compulsory requirements of the fresh SCC. For green concrete requirements, the best CBA content to replace NFA has been found to be $10 \%$ (Ibrahim et al., 2015). Taking into account the mechanical properties of SCC mixture in the literature studies, it was found that the optimal percentage of CBA can replace NFA up to $20 \%$. Furthermore, the advantageous effects of CBA have also been observed in some important studies, as most of the mechanical properties of SCCs obtained by adding only 10\%-15\% CBA instead of NFA improved overall performance (Aswathy \& Mathews, 2015). Likewise, it was observed that SCC obtained by replacing $10 \%$ NFA with CBA has the same behavior. The compressive and indirect tensile strength is increased about $20 \%$ with the assimilation of $15 \%$ CBA (Abidin et al., 2014; Jamaluddin et al., 2016). Few authors have investigated the tensile strength of SCC and it was perceived that NFA can be effectively replaced by CBA without compensating the overall performance at various curing periods (Dwikojuliardi, 2015). In reference to durability, the water absorption rate is reduced up to $15 \%$ replacement levels of NFA with CBA (Abidin et al., 2014; Ratchayut \& Somnuk, 2008). The optimum level of CBA was found to be $10 \%$ for SCC and in NVC in most of the earlier investigations (Abidin et al., 2014; Jamaluddin et al., 2016). Similarly, an improvement in durability properties has been observed in terms of capillary water 
absorption, electrical resistivity, carbonation resistance and chloride penetration of concrete blended with $10 \%$ of CBA instead of NFA (Cheriaf et al., 1999).

Cement production requires huge energy whereas, Pakistan faces acute crises of energy and the cost of cement is rising resulting in an overall rise in the construction cost. Though, there are so many studies performed on MK as cementitious materials and CBA as fine aggregates individually but there is no experimental study conducted on MK as PC replacement and CBA as fine aggregates together in SCC mixture. Therefore, this study proposes a method that increases the properties of SCC and reduces the cement production, and reducing embodied carbon by replacing cement with local MK and sand replacement with CBA separate and combine in the SCC mixture. Moreover, the numerous tests in terms of slump flow, T50 flow, visual segregation index, V-funnel, L-box, J-ring and sieve segregation were performed to measure the workability of SCC mixtures blended with separate and combine local MK as replacement for cement and CBA as fine aggregates. In addition, the hardening performance was evaluated in terms of compressive, tensile, flexural strength and water penetration depth of SCC mixtures blended with separate and combine local MK as replacement for cement and CBA as fine aggregates.

\section{Materials And Methods}

\subsection{Materials}

Cement Ordinary Portland cement (OPC) from a brand-named Lucky, has been utilized in this experimental study and its physical properties and chemical composition are summarized in Table 1 . The fine aggregates are used which composed of hill sand passing from $4.75 \mathrm{~mm}$, crushed stone passing from $12 \mathrm{~mm}$ and retained on $4.75 \mathrm{~mm}$ sieves. Local Metakaolin Local metakaolin (MK) was produced from local natural material soorh available in billions of tons in district Thatta Sindh, Pakistan, by calcination at $800^{\circ} \mathrm{C}$ for 2 hours. The MK was used as cement replacement at various dosages, after sieving it from a sieve No 325. The SEM images of local MK as shown in Figure 1. Moreover, the chemical composition and physical properties comparison of OPC, soorh and developed MK are presented in Table 1.

\subsection{Mix Proportion}

The SCC mixtures were prepared with water/binder ratio of 0.38 (EFNARC, 2005). Total five mixtures were made in which one mixture was prepared of only cement while other mixtures were made of $5 \%, 10 \%$, $15 \%$ and $20 \%$ of developed MK by the cement's weight. Furthermore, the detail of mix proportions is exhibited in Table 3

\subsection{Methods}

The fresh properties of SCC have been studied out by using the method specified in (EFNARC, 2005). The filling ability tests respected slump flow, V-funnel and T50 flow time test, while passing capability tests, like J-Ring and L-box, were also performed. Moreover, sieve segregation test was carried out. Various trial 
mixes with and without superplasticizers were prepared to develop the SCC. However, the hardened concrete tests were conducted after the achievement of early fresh concrete tests and it was dispensed into the molds. Moreover, the concrete samples were removed from mold on one day after casting and then these samples were kept in curing water tank till the testing day. Hence, the five concrete cube samples were utilized for exploring the compressive strength of SCC after 3, 28 and 180 days under EN 12390-3 (2009). Additionally, the five cylinders were cast for splitting tensile strength of SCC at 3, 28 and 180 days as per as per EN 12390-6 (2009).

The flexural strength test on the prism samples of the OPC control mix and metakaolin modified mixes of self-compacted concrete at the age of 28 days was conducted as per BS EN 12390-5: 2009. Specimens of $500 \mathrm{~mm} \times 100 \mathrm{~mm} \times 100 \mathrm{~mm}$ were cast, and these specimens were used for the given testing age.

The cubical samples $(100 \mathrm{~mm} \times 100 \mathrm{~mm} \times 100 \mathrm{~mm}$ ) were cast and de-molded later 24 hours. After demolding all samples were kept in curing tank for curing for 28 and 180 days and then the specimens were kept in a pressure cell and subjected to a water pressure of $0.5 \mathrm{MPa}$ for 72 hours duration for water penetration depth as per BS EN-12390-8:2000. After subjecting the required water pressure, the samples were divided into two halves in Universal Testing Machine and a water-penetrated moistened surface was measured as water penetration depth.

\subsubsection{Embodied Carbon Assessment}

It was utilized to study the sustainability benefits by using MK and CBA for the carbon content of the concrete mix being assessed. The embodied carbon of materials were obtained from literature study as shown in Table 5. The carbon embodied for concrete mixes was estimated by using Equation (1). The $\mathrm{CO} 2 e$, Wi and $\mathrm{CO} 2 i$ in Equation (1) display the embodied carbon of concrete, weight per unit volume of material and embodied carbon of materials respectively.

$$
\mathrm{CO}_{2 e}=\sum_{i=1}^{n}\left(W_{i} \times \mathrm{CO}_{2 i}\right)
$$

\subsection{Fresh concrete results}

The results of fresh properties of SCC with inclusion of local metakaolin is tabulated in Table 5.

\subsubsection{Slump flow}

The fresh properties of SCC with inclusion of MK were investigated and the outcomes were given in Table 6. The recommended values of slump flow are 650-850mm (EFNARC, 2005). Without using superplasticizers and using $1 \%$ superplasticizers, the observed slump flow of control and MK SCC was less than the recommended values. By using $2 \%$ and $3 \%$ superplasticizers the slump flow of control and 
MK SCC was within the recommended range. As the quantity of MK increased the slump flow decreased due to MK's more specific surface area than that of cement, this outcome of the study is corelated to Guneyisi and Gesoglu, (2008). However, in liquefying action, the use of SP enhances the flowability by dropping plastic viscosity and yielding stress. Moreover, a high slump flow can be accomplished owing to the dissolving action of SP by reducing the water demand which entrapment among flocculated particles. Using $2 \%$ superplasticizer, the observed value of slump flow of control mix within range while CBA SCC has been less than the required slum flow i.e., $650 \mathrm{~mm}$. By using $5 \%, 9 \%, 13 \%$ and $17 \%$ superplasticizer the slump flow of CBA10, CBA20, CBA30, and CBA40-SCC has been observed within the required range of (EFNARC, 2005). As the magnitude of CBA enhanced the slump flow has been reduced due to the porosity of $\mathrm{CBA}$, which saturate more water with a higher content of CBA. The outcome achieved indicated the CBA structures, which have a rough form that decreasing interparticle abrasion among aggregates contrasted with the control mix. This trend has been observed by other researchers (Aswathy \& Mathews, 2015). In the combined utilization of local metakaoiln and CBA, as the quantity of MK and CBA increased more quantity of SP is needed to satisfy the required range of Slump flow. Maximum $22 \%$ SP is used to satisfy the requirment of slump flow of MK20CBA40 mix.

\subsubsection{Funnel}

The recommended values of the $\mathrm{V}$-funnel are 6-12sec (EFNARC, 2005). Without using superplasticizers and using $1 \%$ superplasticizers, the observed V-funnel flow of the control and the MK SCCs exceeded the recommended range. By using $2 \%$ and $3 \%$ superplasticizers the $V$-funnel of the control and the MK SCC were within the recommended range. As the quantity of MK increased, the V-funnel time decreased. The $V$-funnel time displays a distinct tendency to rise with growing in the content of MK. This outcome was deemed that the accumulation of MK in concrete made the mixtures extra viscous. This finding is related to the other research investigations (Guneyisi and Gesoglu, 2008; Hassan et al., 2010). Finally, it was revealed that there is no need of any viscosity modifying agent in concrete mixtures while using MK in concrete. By using $2 \%$ superplasticizer, the observed value of $\mathrm{V}$-funnel test of control mix within range while CBA SCC has been more than the required V-funnel i.e. 12-seconds. By using 5\%, $9 \%, 13 \%$, and $17 \%$ superplasticizer the value of V-funnel test of CBA10, CBA20, CBA30, and CBA40-SCC has been observed within the required range of (EFNARC, 2005). As the quantity of CBA increased the V-funnel has been increased owing to the porosity of CBA contrasted with the control mix. CBA saturate more water with a higher content of CBA. The outcome achieved suggested the CBA structure, which have a rough form that decreasing interparticle abrasion among aggregates and showed the excessive inclusion of coal bottom ash has declined the viscosity of SCC mixtures. This trend has been observed by other researchers (Aswathy \& Mathews, 2015). In the combined utilization of local metakaoiln and CBA, as the quantity of $\mathrm{MK}$ and $\mathrm{CBA}$ increased more quantity of SP is needed to satisfy the required range of $\mathrm{V}$ funnel. Maximum $22 \% \mathrm{SP}$ is used to satisfy the requirment of $\mathrm{V}$ funnel of MK20CBA40 mix.

\subsubsection{T50 flow}


The recommended values of T50 flow time are 2-5sec (EFNARC, 2005). Table 6 indicates the T50 flow time was estimated in the range of $2.80 \mathrm{sec}$ to $4.6 \mathrm{sec}$. As the quantity of MK is increased the T50 flow increased. The outcome was cleared that the T50 flow time of SCC was augmented with addition of $20 \%$ MK. This observation was related to Guneyisi et al., (2009). From Table 4, it was indicated that the T50 flow possessed higher plastic viscosity for a given MK content. With using $2 \%$ superplasticizer, the observed $T_{50}$ flow time of control mix within range while CBA SCC has been less than the required value of $T_{50}$ flow time test i.e., more than 5 seconds. By using $5 \%, 9 \%, 13 \%$, and $17 \%$ superplasticizer the $T_{50}$ flow time of CBA10, CBA20, CBA30, and CBA40-SCC has been observed within the required range of (EFNARC, 2005). As the quantity of $C B A$ enhanced the $T_{50}$ flow time has been improved owing to the porosity of CBA contrasted with the cement because CBA saturated more water with a greater content of $\mathrm{CBA}$. The outcome achieved denoted of the CBA structures, which have the rough form that decreasing interparticle abrasion among aggregates and directed the excessive inclusion of coal bottom ash declined the viscosity of SCC mixtures. This trend has been observed by other researchers (Aswathy \& Mathews, 2015). In the combined utilization of local metakaoiln and CBA, as the quantity of MK and CBA increased more quantity of SP is needed to satisfy the required range of T50 flow. Maximum $22 \% \mathrm{SP}$ is used to satisfy the requirment of T50 flow of MK20CBA40 mix.

\subsubsection{Blocking ratio (L-box test)}

It is utilized to evaluate the flow of SCC concrete and the level by which it is subject to blocking by reinforcement. The results of L-Box tests are shown in Table 6. The recommended values for the L-Box test are 0.8-1.0. Without using superplasticizers and using $1 \%$ superplasticizer, the observed values of control and the MK SCC exceed the recommended range. By using $2 \%$ and $3 \%$ superplasticizers the L-box value of control and the MK SCC were observed within the recommended range. As the quantity of MK increased the L-box is decreased, due to MK's more specific surface area than that of cement. This observation is corelated to Guneyisi and Gesoglu, (2008). By using a $2 \%$ superplasticizer, the observed value of L-box test of control mix within range while CBA SCC has been more than the required value of Lbox \{blocking ratio) i.e., less than 1.0. By using $5 \%, 9 \%, 13 \%$, and $17 \%$ superplasticizer the value of L-Box ratio of CBA10, CBA20, CBA30, and CBA40-SCC has been observed within the required range of (EFNARC, 2005). As the quantity of CBA increased the L-box ratio has also been increased due to a decrease in cohesiveness and a lack of a lack in paste volume of CBA contrasted with the control mix. This trend has been detected by other researchers (Aswathy \& Mathews, 2015). In the combined utilization of local metakaoiln and CBA, as the quantity of MK and CBA increased more quantity of SP is needed to satisfy the required range of L-box. Maximum 22\% SP is used to satisfy the requirment of L-box of MK20CBA40 mix.

\subsubsection{J-Ring}

The recommended values of $\mathrm{J}$ Ring test (EFNARC, 2005) are $0-10 \mathrm{~mm}$. Without using superplasticizers and using $1 \%$ super plasticizers, the observed values of the control and the MK SCC exceeded the recommended values. By using $2 \%$ and $3 \%$ superplasticizers the observed J-Ring values of the control 
and the MK SCC were within the recommended range as shown in Table 6. As the quantity of MK increased, J-Ring decreased due to MK's more specific surface area than that of cement. This similar study is related to Guneyisi and Gesoglu, (2008). By using $2 \%$ superplasticizer, the observed value of Jring test of control mix within range while CBA SCC has been less than the required value of J-ring test i.e., less than $10 \mathrm{~mm}$. By using $5 \%, 9 \%, 13 \%$ and $17 \%$ superplasticizer the J-ring of CBA10, CBA20, CBA30, and CBA40-SCC has been observed within the required range of (EFNARC, 2005; Lauritzen, n.d.). As the magnitude of $\mathrm{CBA}$ increased the J-ring has been reduced due to the porosity of CBA contrasted with the cement. As the measure of CBA augmented the J-ring reduced due to a decrease in cohesiveness and lack in paste volume of CBA contrasted with the control mix. This trend has been witnessed by other researchers (Aswathy \& Mathews, 2015). In the combined utilization of local metakaoiln and CBA, as the quantity of MK and CBA increased more quantity of SP is needed to satisfy the required range of J-Ring. Maximum 22\% SP is used to satisfy the requirment of J-Ring of MK20CBA40 mix.

\subsubsection{Sieve segregation}

The recommended range of sieve segregation is $0-12 \%$ (EFNARC, 2005). Without using superplasticizers and using $1 \%$ superplasticizers, the observed values of the control and the MK SCC exceeded the recommended range. By using $2 \%$ superplasticizers, the J-Ring values of control and MK SCC were within the recommended range as displayed in Table 6. As the quantity of MK increased the sieve segregation increased due to MK's more specific surface area as compared to cement. This similar trend of the experimental study is related to Guneyisi and Gesoglu [29]. By using a 2\% superplasticizer, the observed value of sieve segregation of control mix within range while CBA SCC has been less than the required sieve segregation i.e., less than $12 \%$. By using $5 \%, 9 \%, 13 \%$, and $17 \%$ superplasticizer the value of sieve segregation of CBA10, CBA20, CBA30, and CBA40-SCC has been observed within the required range of (EFNARC, 2005). As the magnitude of CBA increased the sieve segregation has been reduced owing to the porosity of CBA contrasted with the cement. CBA has saturated more water with a greater content of CBA. The outcome achieved suggested the CBA structure, which have a rough form that decreasing interparticle abrasion among aggregates and showed the excessive inclusion of coal bottom ash declined the viscosity of SCC mixes. This trend has been observed by other researchers (Aswathy \& Mathews, 2015). In the combined utilization of local metakaoiln and CBA, as the quantity of MK and CBA increased more quantity of SP is needed to satisfy the required range of sieve seggregation. Maximum $22 \%$ SP is used to satisfy the requirment of sieve seggregation of MK20CBA40 mix.

The conclusion on the fresh properties of SCC with accumulation of MK exhibited that the use of MK up to $20 \%$, satisfy the performance of fresh-state requirements associated to greater segregation resistance, deformability, passing and filling capabilities using 2 and $3 \%$ SP without using VMA. The utilization of CBA as fine aggregate replacement to develop SCC, as the quantity of CBA is increased more SP is needed to satisfy the requirement of all fresh properties of SCC. Maximum $17 \%$ SP is used for $40 \%$ replacement of fine aggregate with CBA to satisfy the fresh properties of SCC. In the combined utilization of MK as cement replacement and CBA as fine aggregate replacement maximum $22 \% \mathrm{SP}$ is used to develop the SCC. 


\subsection{Hardened concrete results}

The compressive, tensile, flexural strength and water penetration depth were performed on hardened concrete for all SSC mixes.

\subsubsection{Compressive strength}

Figure 2 shows maximum compressive strength is increased as $22.6 \%, 10.39 \%$, and $9.29 \%$ more than that of control mix at $15 \%$ of MK as cementitious component at 3, 28 and 180 days respectively. However, it was deemed that the compressive Strength of SCC with inclusion of 5\% to $15 \%$ MK is more than that of the SCC without addition of MK as cementitious substantial. This increment may due to the influence by the active pozzolanic reaction of MK and the silica content in MK particles enhances the development of C-S-H, a gel responsible for strength development (Wild et al., 1996; Guru et al., 2013). The major factors that contribute to the strength of MK SCC are (i) the filling consequence, (ii) the dilution consequence (iii) the pozzolanic response of MK with CH (Wild et al., 1996; Khatib and Hibbert, 2005; Said-Mansour et al., 2011). Besides, the compressive strength of SCC was estimated reduced while utilizing the MK more than 15\% (Yasin, 2012). This study is similar to Parande et al., (2008) where it was described that the accumulation of $15 \% \mathrm{MK}$ as cementitious constituent gives an excellent result than the other substitution levels. The almost same trend of results of compressive strength of concrete using metakaolin has been observed by different researchers (Poon et al., 2006; Mermerdaş et al., 2012). Wild and J M Khatib, (1996) and Ding et al., (2002) analyzed that the compressive strength of concrete with inclusion of $20 \%$ and $25 \%$ MK was lower than that of concrete with accumulation of $15 \%$ MK due to the dilution effect of clinker. The dilution effect of clinker is a result of replacement level for cement with an equal extent of MK. In MK concrete, the filler consequence, pozzolanic reaction of $\mathrm{MK}$ with $\mathrm{CH}$, and compounding influence respond as opposed to the dilution effects (Wild et al., 1996; Parande et al., 2008; Ding and Li, 2002). Hassan et al., (2010) stated that the compressive strength was enhanced by $22 \%$ while using $25 \%$ of MK by the weight of cement after 28 days. Vejmelkovaa et al., (2011) conveyed that the MK used in SCC provides compressive strength raises quickly at the initial stage of hardening. Similarly, Melo and Carneiro, (2010) presented that the content of MK increases in SCC that results in reducing the compressive strength of SCC (Okan et al., 2012).

Figure 2 indicates the compressive strength of SCC with accumulation of MK is improved at early age (328 days) as well as later age 180 days. Though, the frequency of strength growth was more important at the early age. The latter study was related to the outcomes obtained in earlier studies (Wild et al., 1996; Abidin et al., 2014). Additionally, it was informed that the highest input to the strength progress of concrete on initial periods due to the pozzolanic reaction of MK (Poon et al., 2001).

It is obvious from figure 3 that compressive strength of CBA SCC mix is enhanced as compared to control mix with the replacement of F.A by CBA; with the substitution range $10 \%$ to $30 \%$. It is oblivious that the optimum compressive strength, $41.56 \mathrm{MPa}$ (i.e. $14.55 \%$ increase contrasted with the control mix) at 28 days, has been attained at $30 \%$ replacement of F.A with CBA. This has happened due to the permeable refinement and pozzolanic response of bottom ash in the concrete matrix (Norul et al., 2001). On further 
substitution of F.A by CBA, the compressive strength of SCC mix blended with CBA is reduced than that of concrete without $\mathrm{CBA}$. This indicated that the strength of concrete mixture was declined with enhance in the magnitude of CBA, owing to the substitution of the resilient substantial with the fragile ingredient and enhanced porosity. The reduction in the free water content of concrete with addition of CBA has happened owing to the saturation of part of water by the permeable particles of the coal bottom ash internally also contributed to some extent in excluding adverse the influence of the aspects accountable for decreased compressive strength (Aswathy \& Mathews, 2015). In the combined utilization of MK as cement replacement and CBA as fine aggregate replacement maximum compressive strength $44.81 \mathrm{MPa}$ is observed at $10 \% \mathrm{MK}$ as cement replacement with $30 \%$ replacement of fine aggregate with CBA which is $23.51 \%$ more than that of control mix at 28 days.

Figure 4 reveled that by the combined use of local metakaolin and CBA maximum compressive strength is $44.81 \mathrm{MPa}$ achieved at 28 days at $10 \%$ replacement of cement with metakaolin combined with $30 \%$ replacement of fine aggregate with coal bottom ash which is $23.51 \%$ more than that of control SCC.

\subsubsection{Splitting tensile strength}

Figure 5 shows that split tensile strength of SCC with inclusion of $5 \%$ to $20 \%$ MK is more than that of the SCC without addition of MK as cementitious substantial. As shown in Figure 2, the maximum split tensile strength is increased as $10.43 \%, 10.19 \%$, and $10.0 \%$ respectively than that of control mix at 3.28 and 180 days respectively at $15 \%$ substitution of cement with metakaolin. This may be due to the effect by the active pozzolanic reaction of MK and silica content in MK particles enhances the formation of $\mathrm{C}-\mathrm{S}-\mathrm{H}$, a gel responsible for strength development (Wild et al., 1996; Guru et al., 2013). On extra substitution of cement by MK the split tensile strength of MK SCC is declined than that of control concrete (Rahmat and Yasin, 2012). This similar trend of this study is related to that where it was observed about tensile strength of SCC with accumulation of $5 \%$ to $15 \%$ MK is achieved maximum than that of control mixes (Billong et al., 2011).

Figure 6 illustrates that split tensile strength of CBA SCC mixture is enhanced as compared to control mix with the replacement of F.A by CBA; with the substitution limit from $10 \%$ to $30 \%$. It is oblivious that the optimum split tensile strength, $4.16 \mathrm{MPa}$ (i.e. $14.6 \%$ enhanced contrasted with the control mix) at 28 days, has been attained at $30 \%$ replacement of F.A with CBA. On further replacement of F.A by CBA, the split tensile strength of CBA SCC concrete is declined than that of control mix concrete. The outcomes proposed that the attachment between cement paste and aggregate has been the most significant aspect in influencing the stability of concrete especially the tensile strength. The enhance in the substitution status of coal bottom ash had formed more permeable concrete with high permeability spread round the CBA aggregate surface, hence decreasing its stability. This trend has been observed by other researchers (Aswathy \& Mathews, 2015). M.P. Kadam et al., (2014) have explored that the tensile strength has been enhanced while using 10\%-30\% substitution and after that it has been reduced for the rest substitution after $7^{\text {th }}, 28^{\text {th }}, 56^{\text {th }}$, and $112^{\text {th }}$ days respectively. According to K. Soman et al., (2014) detected that the tensile strength has been enhance by $0.70 \%, 5.70 \%$, and $12.16 \%$ which is recorded for $10 \%, 20 \%$, and $30 \%$ 
substitution after 7 days correspondingly. In the combined utilization of MK as cement replacement and CBA as fine aggregate replacement maximum tensile strength $4.48 \mathrm{MPa}$ is observed at $10 \% \mathrm{MK}$ as cement replacement with $30 \%$ replacement of fine aggregate with CBA which is $23.42 \%$ more than that of control mix at 28 days.

It is observed from figure 7 that by the combined use of local metakaolin and CBA maximum tensile strength is $4.48 \mathrm{MPa}$ achieved at 28 days at $10 \%$ replacement of cement with metakaolin combined with $30 \%$ replacement of fine aggregate with coal bottom ash which is $23.42 \%$ more than that of control SCC.

\subsubsection{Flexural Strength}

The figure 8 reveals that the maximum flexural strength is increased as $7.07 \%$ more than that of control mix at $15 \%$ of MK as cementitious component at 28 days. However, it was deemed that the flexural Strength of SCC with inclusion of $5 \%$ to $15 \%$ MK is more than that of the SCC without addition of MK as cementitious substantial. This increment may due to the influence by the active pozzolanic reaction of MK and the silica content in MK particles enhances the development of $\mathrm{C}-\mathrm{S}-\mathrm{H}$, a gel responsible for strength development (Guru et al., 2013; Wild et al., 1996). Moreover, further addition of MK in SCC obtained reducing in flexural strength of SCC as compared to SCC without inclusion of MK.

Figure 9 shows that flexural strength of CBA SCC concrete is enhanced as compared to control mix with the substitution of F.A by CBA; with the substitution limit from $10 \%$ to $40 \%$. It is oblivious that the optimum flexural strength, $6.65 \mathrm{MPa}$ (i.e. 14.65\% enhance contrasted with the control mix) at 28 days, has been attained at $30 \%$ replacement of F.A with CBA. On further replacement of F.A by CBA, the flexural strength of CBA SCC concrete is declined as compared to control mix concrete. The coal bottom ash supplanting (CBA30) provided optimum flexural strength. The reduced flexural strength of the sample as the substitution status of coal bottom ash enhanced has been alleged due to the weak interparticle abrasion among the aggregate, as bottom ash particles has been sphere-shaped. This study is concerned with Bhuvaneshwari et a/ have been stated that concrete with a 30\% substitution of bottom ash (BA) with sand indicated more flexural strength for normal samples (Bhuvaneshwari and Murali, 2013). M.P. Kadam et al., (2014) investigated that the flexural strength has been enhanced up to $30 \%$ replacement of BA and beyond it gets reduced. Soman et al., (2014) has also detected that $30 \%$ substitution of fine aggregate by bottom ash contributed comparable flexural strength at the curing period of 28 days. In the combined utilization of $\mathrm{MK}$ as cement replacement and CBA as fine aggregate replacement maximum flexural strength $7.17 \mathrm{MPa}$ is observed at $10 \% \mathrm{MK}$ as cement replacement with $30 \%$ replacement of fine aggregate with CBA which is $23.62 \%$ more than that of control mix at 28 days.

It is observed from figure 10 that by the combined use of local metakaolin and CBA maximum flexural strength is $7.17 \mathrm{MPa}$ achieved at 28 days $10 \%$ replacement of cement with metakaolin combined with $30 \%$ replacement of fine aggregate with coal bottom ash which is $23.62 \%$ more than that of control SCC.

\subsubsection{Water Penetration Depth}


The permeability is one of the most important parameters of concrete durability. The less permeability of concrete shows enhanced resistance against chemical attacks. Once water enters into the concrete, various soluble salts together with chloride ions infiltrate into concrete and cause corrosion. In general, it gives the impression that lesser permeability shows improved durability in concretes (Wesche et al., 1989; Ramezanianpour et al., 2011). Permeability of concrete can be evaluated by the water penetration test and the validity of the water penetration test has been approved by BS EN 12390-8 (2000).

The water penetration depth test presented in Figure 11 revealed that the water penetration depth of SCC mixtures with accumulation of $5 \%$ to $15 \%$ MK is decreased than that of SCC without MK at 28 and 180 days. However, the maximum reduction in water penetration depth of SCC mixtures was found as $34.0 \%$ and $33 \%$ at $15 \%$ of MK as cementitious ingredient at 28 and 180 days respectively. This may due to the filling consequence and effect by the active pozzolanic reaction of Metakaolin and the silica content in metakaolin (Parande et al., 2008; Wild et al., 1996). Almost the same behavior in terms of water penetration is reported by Erhan Guneyisi et al. that the permeability was reduced by $29 \%$ at $15 \%$ of MK as cementitious constituent as compared to plain concrete (Güneyisi et al., 2012).

The water penetration test presented in Figure 12 is covered that the water penetration depth of modified mixes has been reduced contrasted with the CM with the replacement of F.A by the CBA with $10 \%$ to $30 \%$. The optimum reduction in water penetration depth was found as $13.5 \mathrm{~mm}$ (i.e. $33.49 \%$ decrease compared to control mix mix) at $30 \%$ substitution of F.A with CBA. On additional substitution of F.A by CBA, the water penetration depth of CBA SSC concrete has been enhanced contrasted the control mix concrete after 28 days. Almost the same behavior in terms of water penetration has been reported by different researchers (Sirivivatnanon, 1997; Ratchayut \& Somnuk, 2008). However, the water penetration test presented in Figure 12 has shown that the water penetration depth of modified mixes has been declined contrasted with the CM by the replacement of F.A by the CBA with $10 \%$ to $30 \%$. The optimum reduction in water penetration depth has been found as $10.2 \mathrm{~mm}$ (i.e. $41.04 \%$ decrease compared to control mix) at $30 \%$ substitution of F.A with CBA. On additional substitution of F.A by CBA, the water penetration depth of CBA SSC concrete has been increased contrasted with the control mix concrete after 180 days. The same behavior in terms of water penetration has been reported by Yahya et al., (2019) that the substitution of $20 \%$ fine aggregate with CBA, the water penetration depth has been enhanced with growing in the extent of CBA as sand substitution. It was identified that the CBA used as sand substitution has declined concrete resistance for water absorption. This similar study has been detected by Marto et al., (2011). Hashemi et al., (2018) described that the growing need for water has happened owing to the permeable texture of CBA causing in enhance the permeability of concrete. Hence, the CBA saturated high amount of water in concrete contrasted with that of the control mix. Therefore, this occurrence illustrates the CBA to have more porous behavior contrasted with the control mix concrete (Hassan et al., 2010). Almost the same behavior in terms of water penetration has been reported by different researchers (Ratchayut \& Somnuk, 2008; Khatri and Sirivivatnanon, 1997).

It is observed from Figure 13 that by the combined use of local metakaolin and CBA, minimum water penetration depth $9.76 \mathrm{~mm}$ is achieved at 28 days at $10 \%$ replacement of cement with metakaolin 
combined with $30 \%$ replacement of fine aggregate with coal bottom ash which is $36.45 \%$ less than that of control SCC.

\subsubsection{Sustainability assessment}

Table 4 shows the data of embodied carbon for materials which are used in this investigational study and Equation (1) was used to calculate the quantity of embodied carbon content for twenty five SCC mixtures including various percentages of MK as PC replacement and CBA as sand ingredient. Figure 14 indicates the embodied carbon of SCC mixture inclusion with $0 \%-20 \%$ of MK as cementitious material. The embodied carbon is recorded by $2.72 \%, 5.44 \%, 8.10 \%$ and $10.72 \%$ at $5 \%, 10 \%, 15 \%$ and $20 \%$ of PC replaced with MK is lower than that of control mix of SCC. It was perceived that the embodied carbon is decreased as the dosages of PC replaced with MK increases in SCC mixture. This similar type of trend was performed by Bheel et al. (2021) where the embodied carbon is reduced as the content of coconut shell ash rises in concrete. Related studies were observed by Bheel et al. (2020). However, Figure 15 represents the embodied carbon of SCC mixture including $10 \%-40 \%$ of CBA as replacement for fine aggregates in mixture. The embodied carbon of SCC mixture is noted by $0.50 \%, 1.16 \%, 1.82 \%$ and $2.50 \%$ at $10 \%, 20 \%, 30 \%$ and $40 \%$ of fine aggregates replaced with CBA is higher than that of control mix of SCC. It can be observed that the embodied carbon of SCC is increased with growing in the extent of CBA as sand replacement in SCC mixture. Figure 16 displays the calculated quantity of embodied carbon of SCC including $0 \%-20 \%$ of MK as PC replacement and CBA as sand replacement in SCC mixture. The highest embodied carbon is calculated by $450.45 \mathrm{kgCO}_{2} / \mathrm{m}^{3}$ at control mix of SCC and minimum embodied carbon is noted by $405.15 \mathrm{kgCO}_{2} / \mathrm{m}^{3}$ at $20 \%$ of PC replaced with $\mathrm{MK}$ and $10 \%$ of fine aggregates replaced with CBA in SCC mixture. From Figure 16, it has been observed that the embodied carbon is reduced as the dosages of PC replaced with MK and fine aggregates replaced with CBA increases in the SCC mixture. Therefore, when using environmentally friendly materials (such as recycled waste), the embodied carbon in the concrete mix can be more reduced.

\section{Conclusions}

It was concluded from the conducted research that:

- It was detected that by using local Metakaolin and CBA resulted increased amount of superplasticizer to develop the SCC. To develop SCC by using local metakaolin as cement replacement for $5,10,15$ and $20 \%$ metakaolin $2 \%$ and $3 \%$ SP are used respectively. While to develop SCC with CBA as $10,20,30$, and $40 \%$ fine aggregate replacement $5 \%, 9 \%, 13 \%$ and $17 \%$ superplasticizer is used. . In the combined utilization of MK as cement replacement and CBA as fine aggregate replacement maximum $22 \%$ SP is used to develop the SCC.

- The maximum compressive strength is improved as $22.6 \%, 10.39 \%$, and $9.29 \%$ and maximum tensile strength is augmented as $10.43 \%, 10.19 \%$, and $10.0 \%$ more than that of control mix at $15 \%$ of $\mathrm{MK}$ as cementitious component at 3,28 and 180 day respectively. It is oblivious that the optimum compressive strength, $41.56 \mathrm{MPa}$ (i.e. $14.55 \%$ increase contrasted with the control mix) at 28 days, 
has been attained at $30 \%$ replacement of F.A with CBA. By the combined use of local metakaolin and CBA maximum compressive strength is $44.81 \mathrm{MPa}$ achieved at 28 days at $10 \%$ replacement of cement with metakaolin combined with $30 \%$ replacement of fine aggregate with coal bottom ash which is $23.51 \%$ more than that of control SCC. By the combined use of local metakaolin and CBA maximum tensile strength is $4.48 \mathrm{MPa}$ achieved at 28 days at $10 \%$ replacement of cement with metakaolin combined with $30 \%$ replacement of fine aggregate with coal bottom ash which is $23.42 \%$ more than that of control SCC.

- By the combined use of local metakaolin and CBA maximum flexural strength is $7.17 \mathrm{MPa}$ achieved at 28 days $10 \%$ replacement of cement with metakaolin combined with $30 \%$ replacement of fine aggregate with coal bottom ash which is $23.62 \%$ more than that of control SCC.

- The water penetration depth of SCC mixtures with accumulation of $5 \%$ to $15 \% \mathrm{MK}$ is decreased than that of SCC without MK and with $20 \%$ MK after 28 and 180 days. However, the maximum reduction in water penetration depth of SCC mixtures was found as $34.0 \%$ and $33 \%$ at $15 \%$ of MK as cementitious ingredient after 28 and 180 days respectively. The optimum reduction in water penetration depth was found as $13.5 \mathrm{~mm}$ (i.e. $33.49 \%$ decrease compared to control mix mix) at $30 \%$ substitution of F.A with CBA. By the combined use of local metakaolin and CBA, minimum water penetration depth $9.76 \mathrm{~mm}$ is achieved at 28 days at $10 \%$ replacement of cement with metakaolin combined with $30 \%$ replacement of fine aggregate with coal bottom ash which is $36.45 \%$ less than that of control SCC.

- The embodied carbon is reduced with growing in the dosages of MK as PC replacement in SCC mixture. However, the embodied carbon of SCC mixture is increased as the extent of CBA as sand ingredient replacement rises in mixture. Moreover, the embodied carbon of SCC mixture is reduced while the increasing of $\mathrm{MK}$ as cementitious ingredients and $\mathrm{CBA}$ as fine aggregates replacement in mixture.

- Based on investigated parameters, it can be concluded that at $15 \%$ replacement of cement with local metakaolin is optimum and gave better results as compared to control SCC. At $30 \%$ replacement of fine aggregate is optimum and gave better results as compared to control SCC. In the combined mix $10 \%$ replacement of cement with metakaolin combined with $30 \%$ replacement of fine aggregate with coal bottom ash is optimum and gave better results as compared to control SCC.

\section{Declarations}

\section{Funding Statement}

None

\section{Author Contributions}

Manthar Ali Keerio: Data Analysis, Validation, Writing - Original Draft.

Abdullah Saand: Supervision, Methodology, Writing - Original Draft, Funding Acquisition. 
Aneel Kumar: Formal Analysis, Validation.

Naraindas Bheel: Conceptualization, Investigation, Data Analysis, Validation, Writing - Original Draft, Writing - Review and Editing.

Karm Ali: Data Analysis, Validation, Writing - Original Draft

\section{Availability of data and material}

The data used in this study will be made available upon the request.

\section{Compliance with ethical standards/Conflict of interest}

None

\section{Consent to participate}

Not Applicable

\section{Consent for publication}

Not Applicable

\section{Acknowledgement}

The authors are grateful to Quid-e-Awam University of Engineering, Science and Technology Nawabshah for providing required tools to conduct this research study.

\section{References}

Marto, A.R. Awang, A.M. Makhtar (2011), “Compaction Characteristics and Permeability Of Tanjung Bin Coal Ash Mixtures", in: IPCBEE in Proc. of the International Conference on Environment Science and Engineering: Selected Papers. Ed. By IACSIT Press, Singapore: pp. 134-137.

Saand, M. A. Keerio, D. K. Bangwar, M. K. Samo, 2016. Development of metakaolin as a pozzolanic material from local natural material Soorh, Arabian Journal for Science and Engineering, 41 (12), 49374944.

Abidin N.E.Z., Ibrahim M.H.W., Jamaluddin N.,, Kartini K., Hamzah A.F.,, The Effect of Bottom Ash on Fresh Characteristic, Compressive Strength and Water Absorption of Self-Compacting Concrete, Applied Mechanics and Materials Vol. 660 (2014) pp 145-151.

Aswathy P.U \& Mathews M.P., Behaviour of Self Compacting Concrete by Partial Replacement of Fine Aggregate with Coal Bottom Ash, International Journal of Innovative Research in Advanced Engineering (IJIRAE) ISSN: 2349- 2163 Issue 10, Volume 2 (October 2015). 
Badogiannis, E., Tsivilis, S., (2009). Exploitation of poor Greek kaolins, durability of metakaolin concrete. Cem. Concr. Compos. 31, 128-133.

Batis G, Pantazopoulou P, Tsivilis S, Badogiannis E. (2005). The effect of metakaolin on the corrosion behavior of cement mortars. Cem Concr Compos, 27, 125-30.

Bheel, N. and Adesina, A., 2020. Influence of binary blend of corn cob ash and glass powder as partial replacement of cement in concrete. Silicon, pp.1-8.

Bheel, N., Mahro, S.K. and Adesina, A., 2021. Influence of coconut shell ash on workability, mechanical properties, and embodied carbon of concrete. Environmental science and pollution research, 28(5), pp.5682-5692.

Billong, N., et al., (2011). Improving Hydraulic Properties of Lime-Rice Husk Ash (Rha) Binders with Metakaolin (Mk). Construction and Building Materials, 25 (4), 2157-2161.

Damtoft, J.S., Lukasik, J., Herfort, D., Sorrentino, D., Gartner, E.M., (2008). Sustainable development and climate change initiatives. Cem. Concr. Res. 38 (2), 115-127

Ding, J.-T. and Z. Li, (2002). Effects of Metakaolin and Silica Fume on Properties of Concrete" ACl Materials Journal,99 (4),393-398.

EN, B., 12390-8 (2000). Depth of Penetration of Water under Pressure" British Standards Institution.

Eva, V., Martin, K., Stefania, G., Bartlomiej, S., Robert, C., (2011). Properties of self-compacting concrete mixtures containing metakaolin and blast furnace slag. Constr. Build. Mater. 25, 1325-1331

Flower DJM, Sanjayan JG. Green house gas emissions due to concrete manufacture. Int. J. Life Cycle Assess. [Internet]. $2007 \mathrm{Jul}$ 2;12(5):282-8. Available from:

http://link.springer.com/10.1065/lca2007.05.327

Guneyisi E, Gesoglu M, Ozbay E (2009). Evaluating and forecasting the initial and final setting times of self-compacting concretes containing mineral admixtures by neural network. Mater Struct, 42, 469-84

Guneyisi E, Gesoglu M. (2008) Properties of self-compacting mortars with binary and ternary cementitious blends of fly ash and metakaolin. Mater Struct, 41, 1519-31.

Güneyisi, E., et al., (2012). Strength, Permeability and Shrinkage Cracking of Silica Fume and Metakaolin Concretes. Construction and Building Materials, 34, 120-130.

Guneyisi, E., Gesoglu, M., Mermerdas, K., (2008). Improving strength, drying shrinkage, and pore structure of concrete using metakaolin. Mater. Struct. 41, 937-949.

Guru, J.J., Sashidhar, C., Ramana, R.I.V., Annie, P.J., (2013). Micro and macrolevel properties of fly ash blended self-compacting concrete. Mater. Des. 46, 696-705. 
Hassan AAA, Lachemi M, Hossain KMA (2010). Effect of metakaolin on the rheology of self-consolidating concrete. In: Khayat K, Feys D, editors. Proceedings of SCC 2010 design, production, and placement of SCC, vol. 1. Springer: RILEM Publications. p. 103-12

Hendriks, C.A., Worrell, E., de Jager, D., Blok, K., Riemer, P., (2004). Emission reduction of greenhouse gases from the cement industry. Greenhouse Gas Control Technologies Conference.

Hwang, J.P., Jung, M.S., Lee, C.K., Jin, S.H., Ann, K.Y., (2015). Risk of environmental contamination arising from concrete structures, part I: CO2 emission. KSCE J. Civ. Eng, 19, 1224-1229

Ibrahim M.H.W., Hamzah A.F, Jamaluddin N, Ramadhansyah P.J and Fadzil A.M, Split Tensile Strength on Self-Compacting Concrete Containing Coal Bottom Ash, Procedia - Social and Behavioral Sciences 195 (2015) $2280-2289$.

Jamaluddin N., Hamzah A.F., Ibrahim M.H.W., Ramadhansyah P.J, Arshad M.F., Abidin N.E.Z., Nurol H.D., Fresh Properties and Flexural Strength of Self-Compacting Concrete Integrating Coal Bottom Ash, MATEC Web of Conferences 47, published by EDP Sciences, 2016.

Soman, Divya Sasi and K.A. Abubaker., (2014), "Strength properties of concrete with partial replacement of sand by bottom ash", International Journal of Innovative Research in Advanced Engineering (IJIRAE), ISSN: 2349-2163, Volume 1, Issue 7, pp.223-227.

Kalaw, M. E., Culaba, A., Hinode, H., Kurniawan, W., Gallardo, S., \& Promentilla, M. A. (2016). Optimizing and characterizing geopolymers from ternary blend of Philippine coal fly ash, coal bottom ash and rice hull ash. Materials, 9(7), 580

Khatib, J. and J. Hibbert, (2005), Selected Engineering Properties of Concrete Incorporating Slag and Metakaolin. Construction and Building Materials, 19(6), 460-472.

Khatri .R. P. and Sirivivatnanon. V. (1997), "Role of Permeability in Sulphate Attack" Cement and Concrete Research Vol. 27, No. 8, 1179-89.

Kim HS, Lee SH, Moon HY (2007). Strength properties and durability aspects of high strength concrete using Korean metakaolin. Constr Build Mater, 21, 1229-37.

Lauritzen E.K., Recycling of concrete - an overview of development and challenges, DEMEX Consulting Engineers A/S, Denmark.

Long G, Gao Y, Xie Y. Designing more sustainable and greener self-compacting concrete. Constr. Build. Mater. [Internet]. 2015 Jun;84:301-6. Available from: https://linkinghub.elsevier.com/retrieve/pii/S0950061815002263

Cheriaf, J.C. Rocha, J. Pera, Pozzolanic properties of pulverized coal combustion bottom ash, Cement and Concrete Research. 29 (1999) 1387-1391. 
P. Kadam \& Y. D. Patil, (2014), "The Effect of sieved Coal Bottom Ash as a Sand Substitute on the Properties of Concrete with Percentage Variation in Cement" American Journal of Civil Engineering and Architecture. Vol. 2, No. 5, 160-166

Meddah MS, Ismail MA, El-Gamal S, Fitriani H. Performances evaluation of binary concrete designed with silica fume and metakaolin. Constr. Build. Mater. [Internet]. 2018 Mar;166:400-12. Available from: https://linkinghub.elsevier.com/retrieve/pii/S0950061818301624

Melo KA, Carneiro AMP. Effect of metakaolin's finesses and content in self-consolidating concrete. Construction Building Material, 24,1529-35.

Mermerdaş, K., et al., (2012). Strength Development of Concretes Incorporated with Metakaolin and Different Types of Calcined Kaolins. Construction and Building Materials,37, 766-774.

Mohammed Yahya Mohammed Al-Fasih, Mohd Haziman Wan Ibrahim, Nurul Fasihah Basirun, Ramadhansyah Putra Jaya, Mohd Syahrul Hisyam Mohd Sani.,(2019), " Influence of Partial Replacement of Cement and Sand with Coal Bottom Ash on Concrete Properties" International Journal of Recent Technology and Engineering (IJRTE) ISSN: 2277-3878, Volume-8 Issue-3S3.

Norul Ernida Zainal Abidin, Mohd Haziman Wan Ibrahim, Norwati Jamaluddin, Kartini Kamaruddin and Ahmad Farhan Hamzah, (2001), " The Strength Behavior of Self-Compacting Concrete incorporating Bottom Ash as Partial Replacement to Fine Aggregate"

Okan Karahan,Khandaker, Hossain, Erdogan Ozbay, Mohamed Lachemi, Emre Sancak (2012). Effect of metakaolin content on the properties self-consolidating lightweight concrete. Consytruction and building Material 31, 320-325

Bhuvaneshwari and R. Murali, "Strength Characteristics of Glass Fibre on Bottom Ash Based Concrete", International Journal of Science, Environment and Technology, ISSN (p): 2277-663X, ISSN (e): 2278-3687, Volume 2, No. 1, 2013, pp.90-102.

Papadakis, V.G., Tsimas, S., (2002). Supplementary cementing materials in concrete part I: efficiency and design. Cem. Concr. Res. 32, 1525-1532

Parande AK, Babu BR, Karthik MA, Kumaar KKD, Palaniswamy N (2008). Study on strength and corrosion performance for steel embedded in metakaolin blended concrete/mortar. Constr Build Mater, 22, 127-34.

Poon, C.S., Lam, L., Kou, S.C., Wong, Y.L., Ron, W., (2001). Rate of pozzolanic reaction of metakaolin in high-performance cement pastes. Cem. Concr. Res. 31, 1301-1306.

Poon, C.-S., S. Kou, and L. Lam, (2006). Compressive Strength, Chloride Diffusivity and Pore Structure of High Performance Metakaolin and Silica Fume Concrete. Construction and building materials, 20 (10), 858-865. 
Dwikojuliardi, (2015). Malaysia and construction industry, Malaysia construction research journal. 2(1). 22-45.

Rafat S., Paratibha A., Yogesh A., Mechanical and durability properties of self-compacting concrete containing fly ash and bottom ash, Journal of Sustainable Cement-Based Materials Vol. 1, No. 3, September 2012, 67-82.

Rafat S., Paratibha A., YogeshA.Influence of water/powder ratio on strength properties of selfcompacting concrete containing coal fly ash and bottom ash, Construction and Building Materials 29 (2012) 73-81.

Rafik, A., Salah, A.A., El-Sayed, E., (2010). Properties and durability of metakaolin blended cements: mortar and concrete. Mater. Constr. 60, 33-49

Rahmat Madandoust., Yasin, M.S., (2012). Fresh and hardened properties of self-compacting concrete containing metakaolin. Constr. Build. Mater. 35, 752-760.

Ramezanianpour, A.A., et al., (2011), Practical Evaluation of Relationship between Concrete Resistivity, Water Penetration, Rapid Chloride Penetration and Compressive Strength. Construction and Building Materials, 25 (5), 2472-2479.

Ratchayut K. \&Somnuk T., Properties of Self-Compacting Concrete in Corporating Bottom Ash as a Partial Replacement of Fine Aggregate, ScienceAsia 34 (2008): 087-095.

S.A. Mangi, M.H.W. Ibrahim, N. Jamaluddin, S. Shahidan, M.F. Arshad, S.A. Memon, R.P. Jaya, S.W. Mudjanarko, M.I. Setiawan, Influence of ground coal bottom ash on the properties of concrete, International Journal of Sustainable Construction Engineering and Technology. 9 (2018) 26-34.

S.S.G. Hashemi, H. Bin Mahmud, J.N.Y. Djobo, C.G. Tan, B.C. Ang, N. Ranjbar (2018), “Microstructural characterization and mechanical properties of bottom ash mortar" Journal of Cleaner Production. 170, pp.797-804.

Said-Mansour M, Kadri E, Kenai S, Ghrici M, Bennaceur R., (2011). Influence of calcined kaolin on mortar propertie, Construction Building Materials, 25,2275-2282.

Shekarchi M, Bonakdar A, Bakhshi M, Mirdamadi A, Mobasher B (2010). Transport properties in metakaolin blended concrete. Constr Build Mater, 24, 2217-23.

The European guidelines for self-compacting concrete; specification production and use. EFNARC, May 2005

Turner LK, Collins FG. Carbon dioxide equivalent (CO2-e) emissions: A comparison between geopolymer and OPC cement concrete. Constr. Build. Mater. [Internet]. 2013 Jun;43:125-30. Available from: https://linkinghub.elsevier.com/retrieve/pii/S0950061813000871 
Wesche, K., et al., (1989). Test Methods for Determining the Properties of Fly Ash and of Fly Ash for Use in Building Materials" Materials and Structures, 22 (4), 299-308.

Wild, S., Khatib, J.M., Jones, A., (1996). Relative strength, pozzolanic activity and cement hydration in superplasticised metakaolin concrete. Cem. Concr. Res. 26, 1537-1544.

Yang K-H, Song J-K, Song K-I. Assessment of $\mathrm{CO} 2$ reduction of alkali-activated concrete. J. Clean. Prod. [Internet]. 2013 Jan;39:265-72. Available from:

https://linkinghub.elsevier.com/retrieve/pii/S0959652612004076

Yogesh, A., Rafat, S., Microstructure and properties of concrete using bottom ash and wastefoundry sand as partial replacement of fine aggregates, Construction and Building Materials 54 (2014) 210-223.

\section{Tables}

Table 1: Physiochemical Properties of Binder (OPC, Soorh and Developed Metakaolin)

\begin{tabular}{|l|c|c|c|c|}
\hline Constituent & $\begin{array}{l}\text { OPC } \\
\text { (\%) }\end{array}$ & $\begin{array}{l}\text { Soorh } \\
\text { (\%) }\end{array}$ & $\begin{array}{l}\text { Metakaolin } \\
\text { (\%) }\end{array}$ & $\begin{array}{l}\text { CBA } \\
\text { (\%) }\end{array}$ \\
\hline $\mathrm{SiO}_{2}$ & 20.78 & 55.89 & 62.18 & 36.67 \\
\hline $\mathrm{Al}_{2} \mathrm{O}_{3}$ & 5.11 & 23.51 & 21.67 & 26.131 \\
\hline $\mathrm{CaO}$ & 60.89 & ------ & 3.01 & 5.107 \\
\hline $\mathrm{MgO}$ & 3.0 & 3.53 & 3.41 & 1.757 \\
\hline $\mathrm{Fe}_{2} \mathbf{O}_{3}$ & 3.17 & 8.15 & 3.01 & 14.022 \\
\hline $\mathrm{K}_{2} \mathrm{O}$ & ---- & 5.89 & 1.85 & 0.927 \\
\hline $\mathrm{Na}_{2} \mathrm{O}_{3}$ & ---- & 1.89 & 1.03 & 2.535 \\
\hline $\mathrm{TiO}_{2}$ & ---- & 1.14 & 1.03 & 2.535 \\
\hline $\mathrm{In}_{2} \mathrm{O}_{3}$ & ---- & ---- & 0.80 & \\
\hline $\mathrm{LOI}(\%)$ & 1.71 & 7.40 & 0.50 & 1.064 \\
\hline Specific gravity & 3.15 & 2.64 & 2.60 & \\
\hline
\end{tabular}

Table 2: Constitute composition of natural material Soorh and developed metakaolin

\begin{tabular}{|l|c|c|}
\hline Components & Soorh (\%) & Developed metakaolin (\%) \\
\hline Quartz & 47.1 & 36.3 \\
\hline Illite & 27.4 & 42.9 \\
\hline Stevensite & 12.1 & 16.5 \\
\hline Kalonite & 11.9 & -- \\
\hline Calcite magnesium & 0.8 & 4.3 \\
\hline Hematite & 0.7 & -- \\
\hline
\end{tabular}

Table 3: Chemical composition of CBA 


\begin{tabular}{|c|c|}
\hline Constituents & Percentage by weight of CBA Lakhra power plant \\
\hline $\mathrm{SiO}_{2}$ & 36.67 \\
\hline $\mathrm{Al}_{2} \mathrm{O}_{3}$ & 26.131 \\
\hline $\mathrm{CaO}$ & 5.107 \\
\hline $\mathrm{MgO}$ & 1.757 \\
\hline $\mathrm{Fe}_{2} \mathrm{O}_{3}$ & 14.022 \\
\hline $\mathrm{K}_{2} \mathrm{O}$ & 0.927 \\
\hline $\mathrm{Na}_{2} \mathrm{O}_{3}$ & 2.535 \\
\hline $\mathrm{TiO}_{2}$ & 2.535 \\
\hline
\end{tabular}

Table 4: Details of mix proportions $(\mathrm{Kg} / \mathrm{m} 3)$

\begin{tabular}{|c|c|c|c|c|c|c|c|c|}
\hline Concrete Mix & Cement & MK & CBA & $\begin{array}{c}\text { W/B } \\
(\%)\end{array}$ & Water & FA & CA & $\begin{array}{c}\text { SP } \\
(\%)\end{array}$ \\
\hline CM & 500 & 0 & -- & 0.38 & 190 & 900 & 650 & 2 \\
\hline MK5 & 475 & 25 & -- & 0.38 & 190 & 900 & 650 & 2 \\
\hline MK10 & 450 & 50 & -- & 0.38 & 190 & 900 & 650 & 2 \\
\hline MK15 & 425 & 75 & -- & 0.38 & 190 & 900 & 650 & 3 \\
\hline MK20 & 400 & 100 & -- & 0.38 & 190 & 900 & 650 & 3 \\
\hline CBA10 & 500 & -- & 90 & 0.38 & 190 & 810 & 650 & 5 \\
\hline CBA20 & 500 & -- & 180 & 0.38 & 190 & 720 & 650 & 9 \\
\hline CBA30 & 500 & -- & 270 & 0.38 & 190 & 630 & 650 & 13 \\
\hline CBA40 & 500 & -- & 360 & 0.38 & 190 & 540 & 650 & 17 \\
\hline MK5CBA10 & 475 & 25 & 90 & 0.38 & 190 & 810 & 650 & 5 \\
\hline MK5CBA20 & 475 & 25 & 180 & 0.38 & 190 & 720 & 650 & 9 \\
\hline MK5CBA30 & 475 & 25 & 270 & 0.38 & 190 & 630 & 650 & 13 \\
\hline MK5CBA40 & 475 & 25 & 360 & 0.38 & 190 & 540 & 650 & 18 \\
\hline MK10CBA10 & 450 & 50 & 90 & 0.38 & 190 & 810 & 650 & 5 \\
\hline MK10CBA20 & 450 & 50 & 180 & 0.38 & 190 & 720 & 650 & 12 \\
\hline MK10CBA30 & 450 & 50 & 270 & 0.38 & 190 & 630 & 650 & 16 \\
\hline MK10CBA40 & 450 & 50 & 360 & 0.38 & 190 & 540 & 650 & 20 \\
\hline MK15CBA10 & 425 & 75 & 90 & 0.38 & 190 & 810 & 650 & 7 \\
\hline MK15CBA20 & 425 & 75 & 180 & 0.38 & 190 & 720 & 650 & 13 \\
\hline MK15CBA30 & 425 & 75 & 270 & 0.38 & 190 & 630 & 650 & 17 \\
\hline MK15CBA40 & 425 & 75 & 360 & 0.38 & 190 & 540 & 650 & 22 \\
\hline MK20CBA10 & 400 & 100 & 90 & 0.38 & 190 & 810 & 650 & 7 \\
\hline MK20CBA20 & 400 & 100 & 180 & 0.38 & 190 & 720 & 650 & 13 \\
\hline MK20CBA30 & 400 & 100 & 270 & 0.38 & 190 & 630 & 650 & 17 \\
\hline MK20CBA40 & 400 & 100 & 360 & 0.38 & 190 & 540 & 650 & 22 \\
\hline
\end{tabular}


Table 5: Embodied carbon of materials

$\begin{array}{ccc}\text { Materials } & \begin{array}{c}\text { Embodied carbon } \\ \left(\mathrm{kgCO}_{2} / \mathrm{kg}\right)\end{array} & \text { "References" } \\ \text { Cement } & 0.82 & \text { (Flower and Sanjayan, 2007) (Meddah et al., } \\ \text { MK } & 0.33 & \text { 2018) } \\ \text { CBA } & 0.015 & \text { (Kalaw et al., 2016) } \\ \text { Super } & 0.72 & \text { (Long et al., 2015) } \\ \text { Plasticizer } & 0 & \text { (Yang et al., 2013) } \\ \text { Water } & 0.0139 & \text { (Turner and Collins, 2013) } \\ \text { FA } & 0.0408 & \text { (Turner and Collins, 2013) } \\ \text { CA } & & \end{array}$

Table 6: Fresh properties of SCC

\begin{tabular}{|c|c|c|c|c|c|c|c|}
\hline \multirow{2}{*}{$\begin{array}{l}\text { Concrete } \\
\text { Mix }\end{array}$} & \multicolumn{3}{|c|}{ Filling Ability Properties } & \multicolumn{2}{|c|}{$\begin{array}{c}\text { Passing Ability } \\
\text { Properties }\end{array}$} & \multirow{2}{*}{$\begin{array}{c}\text { Segregation Resistance } \\
\text { Property }\end{array}$} & \multirow{2}{*}{$\left|\begin{array}{|l}\text { SP } \\
(\%)\end{array}\right|$} \\
\hline & $\begin{array}{l}\text { Slump Flow } \\
(\mathrm{mm})\end{array}$ & $\begin{array}{c}\text { V-funnel } \\
\text { (Scec) }\end{array}$ & $\begin{array}{c}\mathrm{T}_{50} \\
\text { flow } \\
\text { (Scec) }\end{array}$ & $\begin{array}{l}\text { L-Box } \\
\text { (Ratio) }\end{array}$ & $\begin{array}{l}\text { J- Ring } \\
(\mathrm{mm})\end{array}$ & & \\
\hline $\mathrm{CM}$ & 740 & 7.4 & 2.8 & 0.83 & 2.5 & 8.43 & 2 \\
\hline MK5 & 710 & 9.8 & 3.6 & 0.95 & 6 & 5.11 & 2 \\
\hline MK10 & 695 & 11.2 & 4.8 & 0.97 & 7.5 & 4.88 & 2 \\
\hline MK15 & 635 & 9.1 & 3.4 & 0.88 & 3.8 & 10.1 & 3 \\
\hline MK20 & 580 & 11.4 & 4.6 & 0.98 & 8.3 & 6.78 & 3 \\
\hline CBA10 & 735 & 11.2 & 4.98 & 0.85 & 4.5 & 5.26 & 5 \\
\hline CBA20 & 760 & 11.89 & 4.89 & 0.92 & 7.4 & 4.56 & 9 \\
\hline CBA30 & 755 & 10.22 & 4.8 & 0.87 & 8.7 & 7.23 & 13 \\
\hline CBA40 & 750 & 12 & 4.3 & 0.89 & 6.8 & 7.35 & 17 \\
\hline MK05CBA10 & 745 & 8.39 & 3.4 & 0.89 & 3.8 & 8.45 & 5 \\
\hline MK05CBA20 & 750 & 10.22 & 3.8 & 0.92 & 7.8 & 6.67 & 9 \\
\hline MK05CBA30 & 750 & 9.84 & 4.3 & 0.9 & 8.1 & 5.72 & 13 \\
\hline MK05CBA40 & 752 & 11.42 & 4.8 & 0.88 & 8.6 & 6.82 & 18 \\
\hline MK10CBA10 & 760 & 8.4 & 3.7 & 0.88 & 3.8 & 6.24 & 5 \\
\hline MK10CBA20 & 745 & 9.5 & 4.4 & 0.89 & 4.2 & 7.18 & 12 \\
\hline MK10CBA30 & 755 & 10.3 & 4.9 & 0.95 & 5.6 & 6.38 & 16 \\
\hline MK10CBA40 & 730 & 10.2 & 4.1 & 0.91 & 8.4 & 6.1 & 20 \\
\hline MK15CBA10 & 745 & 9.7 & 3.9 & 0.91 & 4 & 5.27 & 7 \\
\hline MK15CBA20 & 750 & 10.3 & 4.3 & 0.94 & 4.2 & 6.91 & 13 \\
\hline MK15CBA30 & 755 & 10.5 & 4.8 & 0.9 & 7.3 & 5.79 & 17 \\
\hline MK15CBA40 & 750 & 8.7 & 4.2 & 0.94 & 6.9 & 7.35 & 22 \\
\hline MK20CBA10 & 750 & 9.6 & 4.4 & 0.85 & 5 & 6.39 & 7 \\
\hline MK20CBA20 & 720 & 10.2 & 4.8 & 0.87 & 6.3 & 5.71 & 13 \\
\hline MK20CBA30 & 725 & 11.1 & 3.9 & 0.91 & 6.8 & 6.4 & 17 \\
\hline MK20CBA40 & 745 & 11.66 & 4.3 & 0.95 & 6.2 & 6.24 & 22 \\
\hline
\end{tabular}

\section{Figures}



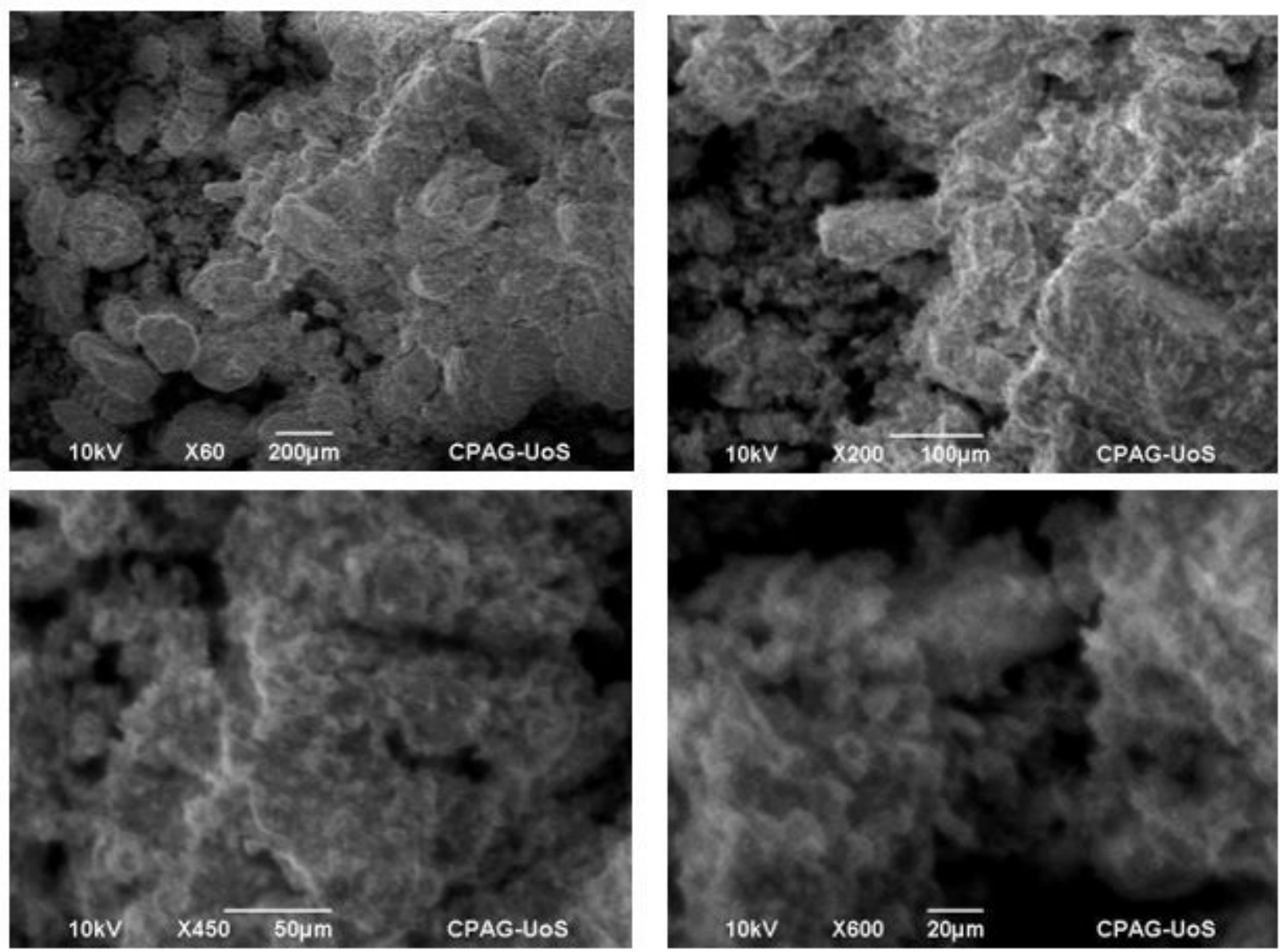

Figure 1

SEM images of local developed metakaolin

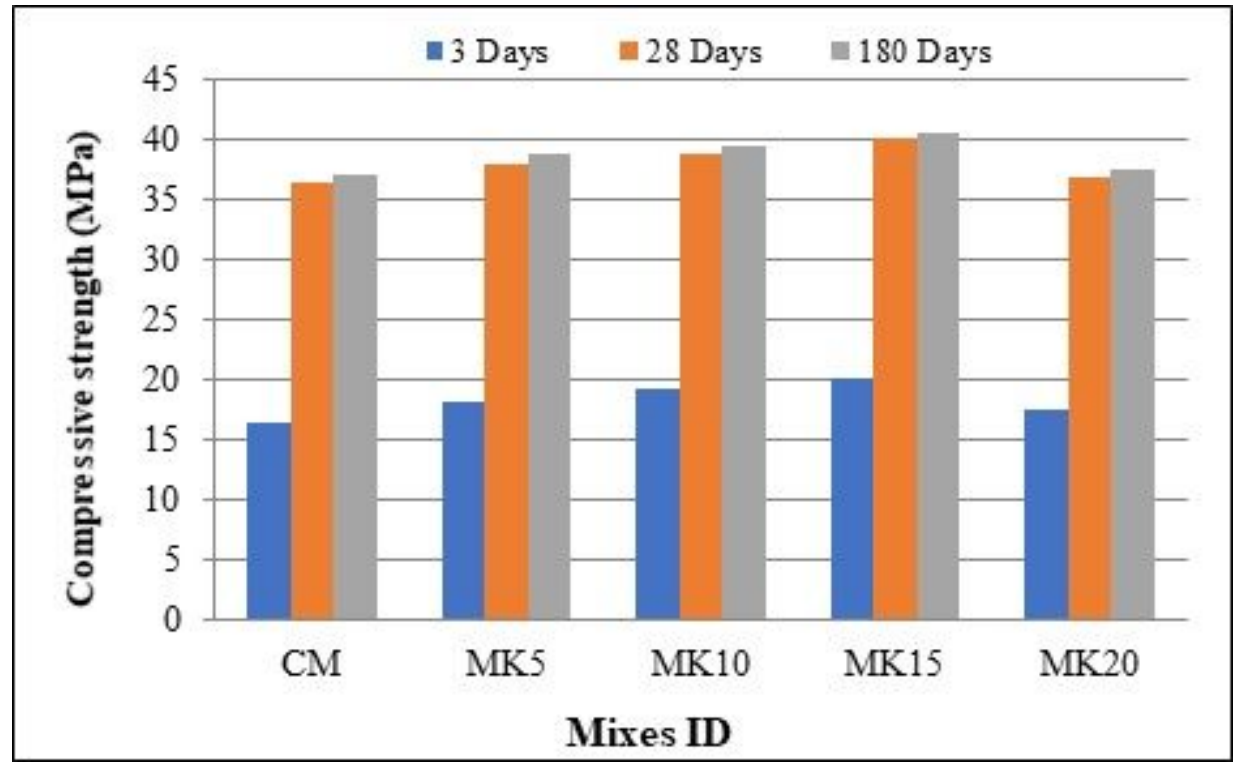

Figure 2

Compressive strength of MK SCC at 3, 28 and 180 days 


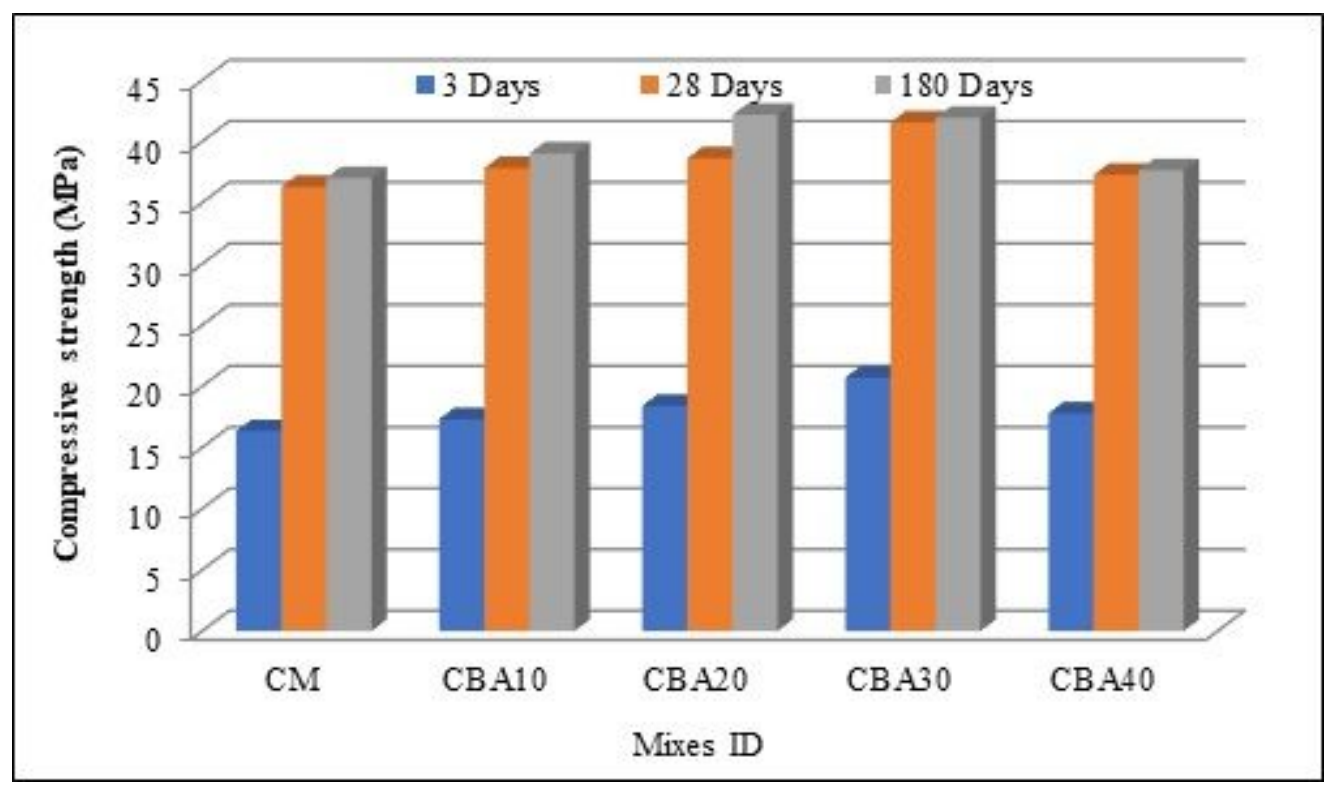

Figure 3

Compressive strength of CBA SCC at 3, 28 and 180 days

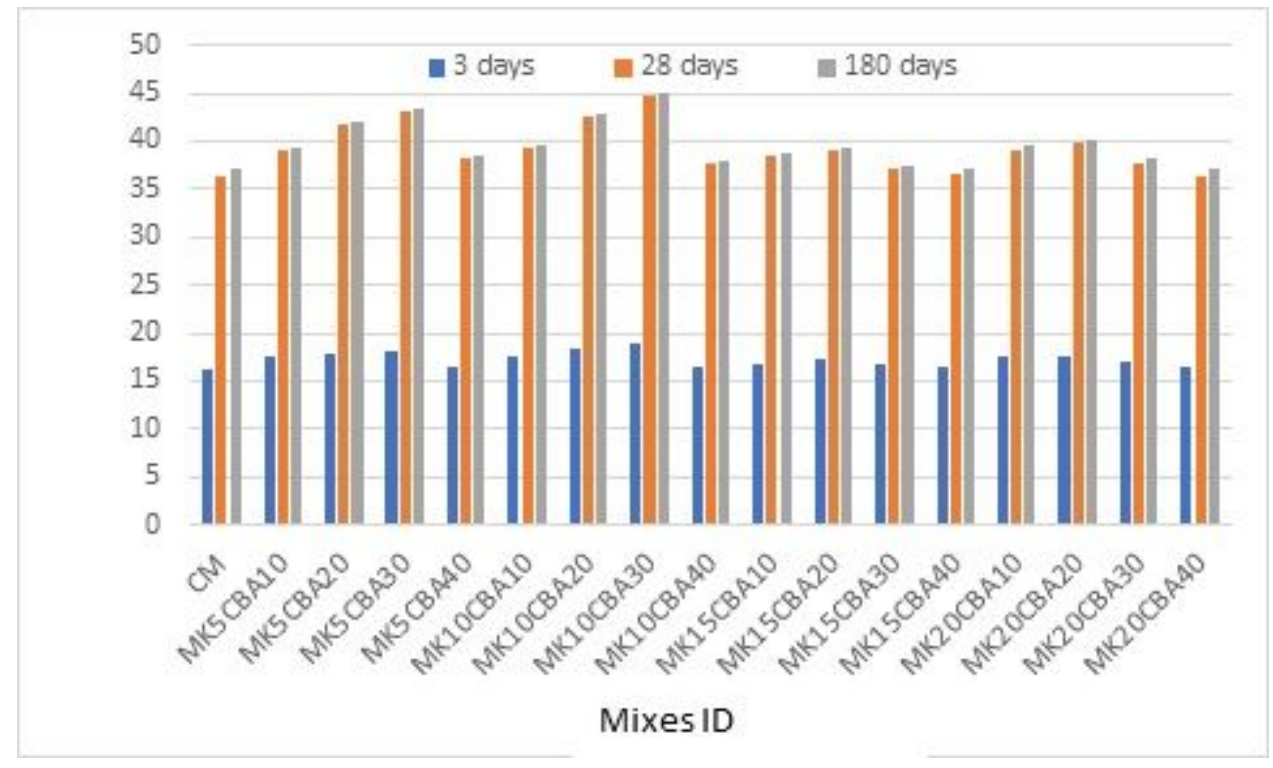

Figure 4

Compressive strength of MK CBA SCC at 3,28 and 180 days 


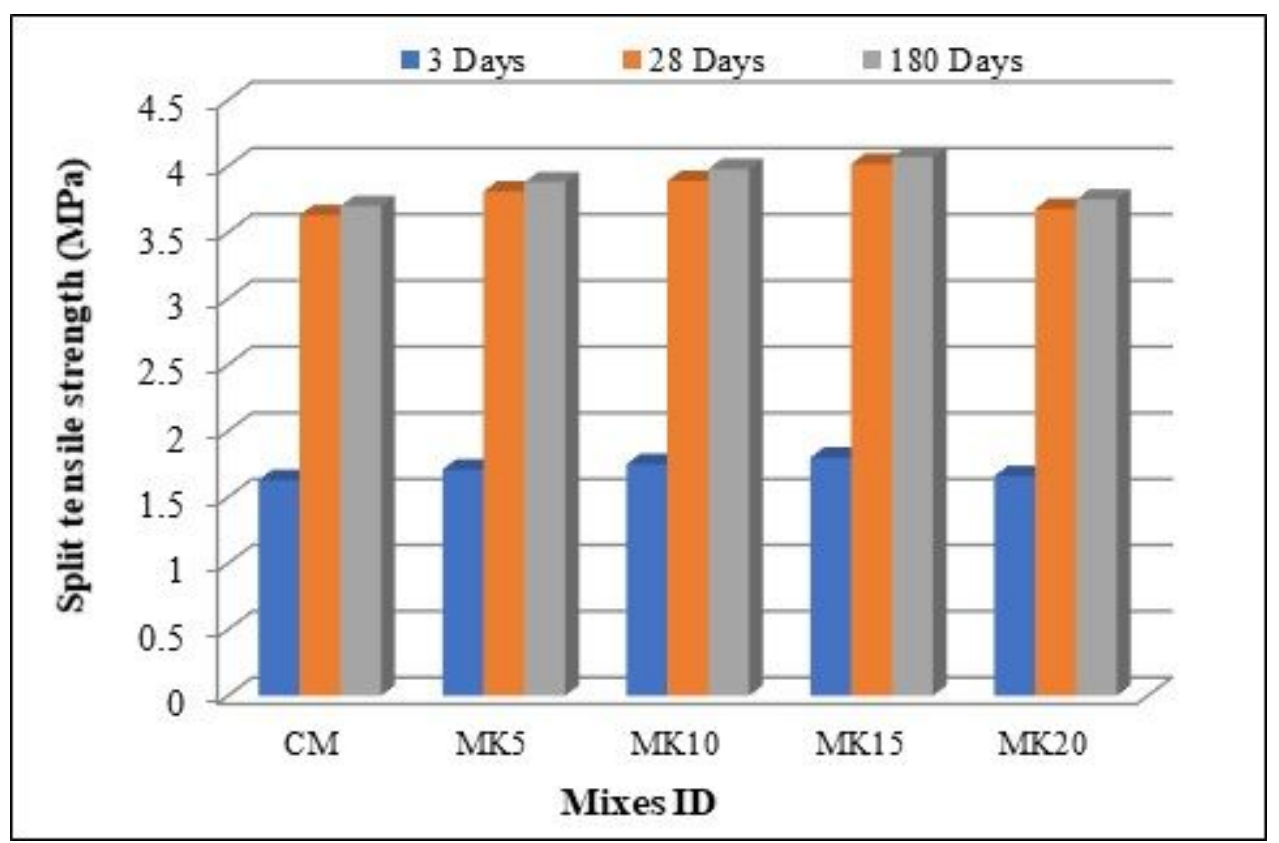

Figure 5

Tensile strength of MK SCC at 3, 28 and 180 days

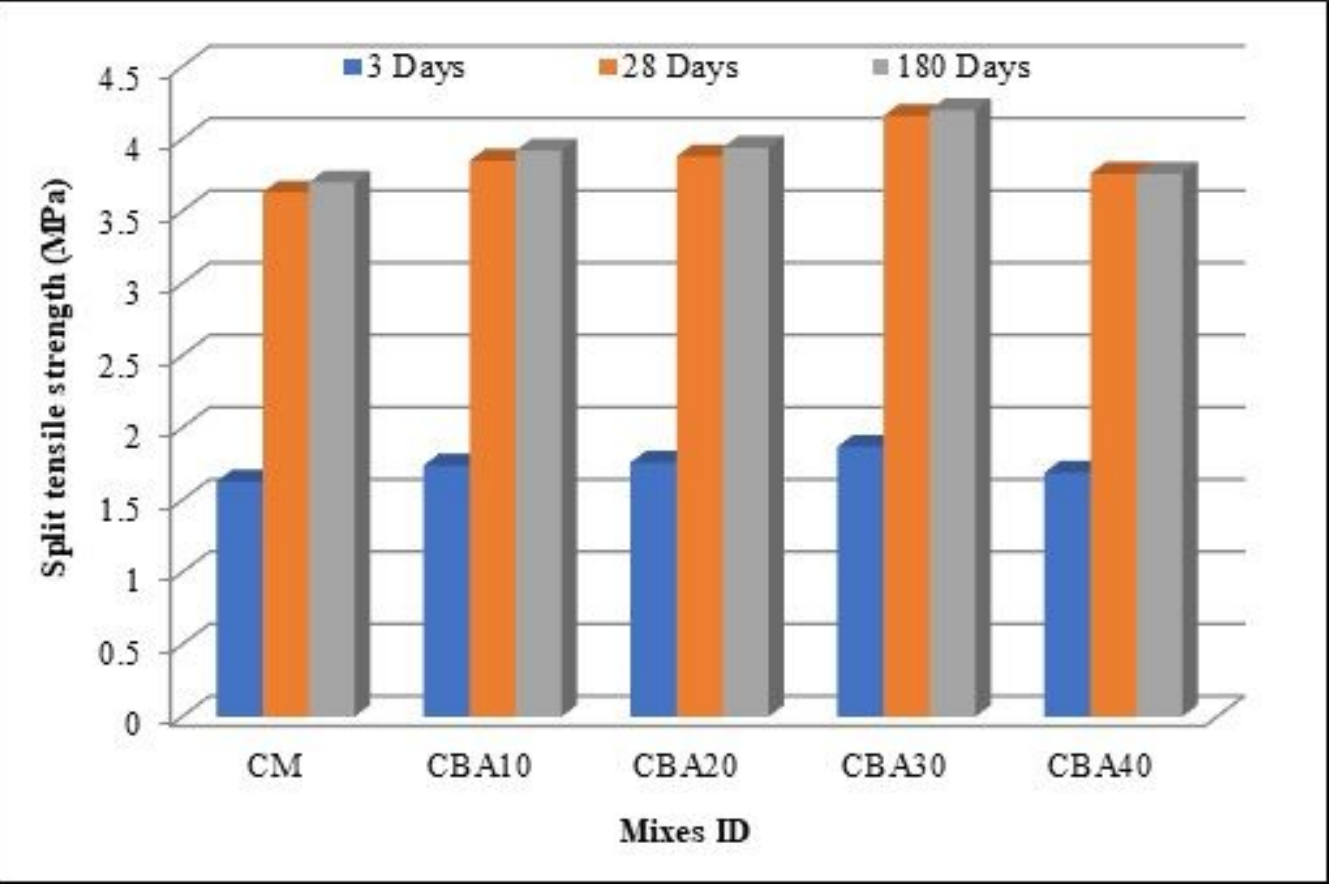

Figure 6

Tensile strength of CBA SCC at 3,28 and 180 days 


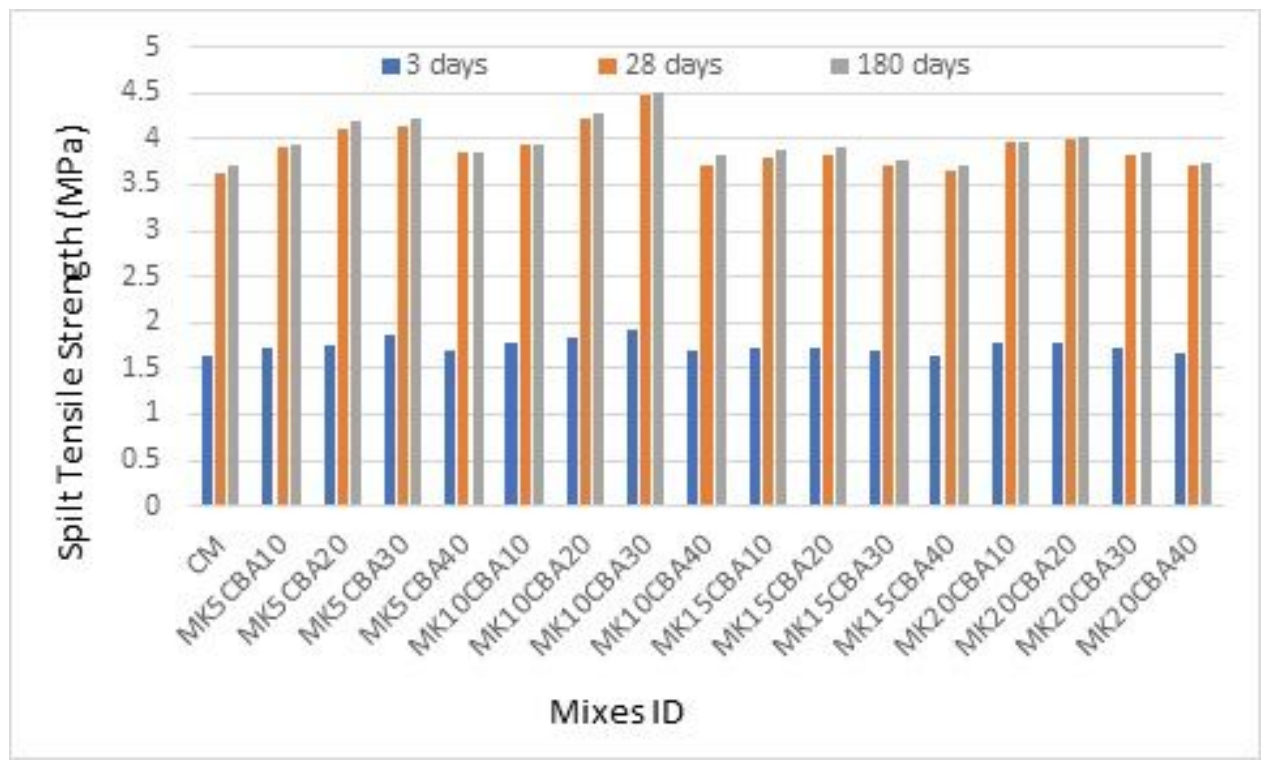

Figure 7

Tensile strength of MK CBA SCC at 3, 28 and 180 days

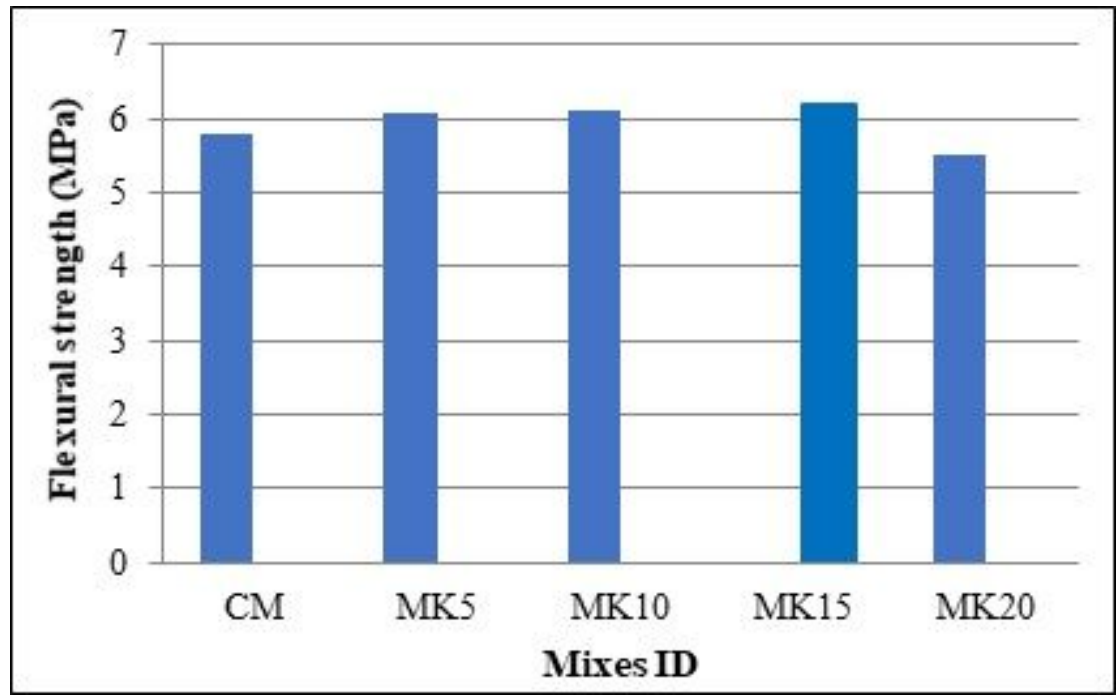

Figure 8

Flexural strength of MK SCC at 28 days 


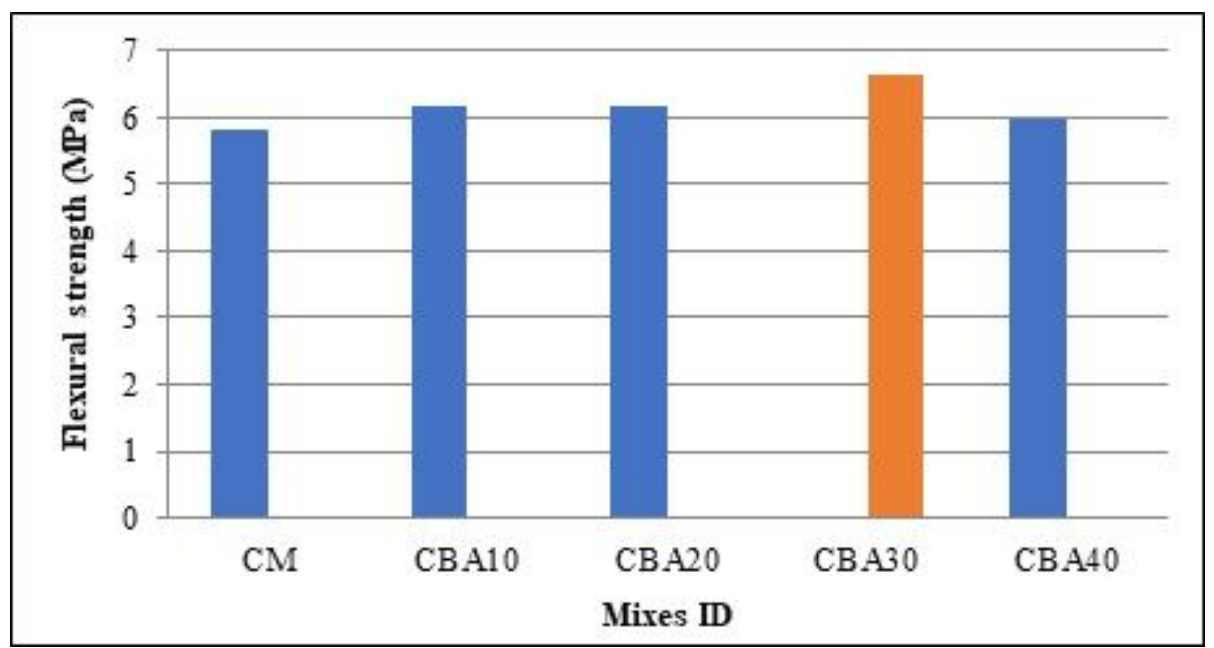

Figure 9

Flexural strength of CBA SCC at 28 days

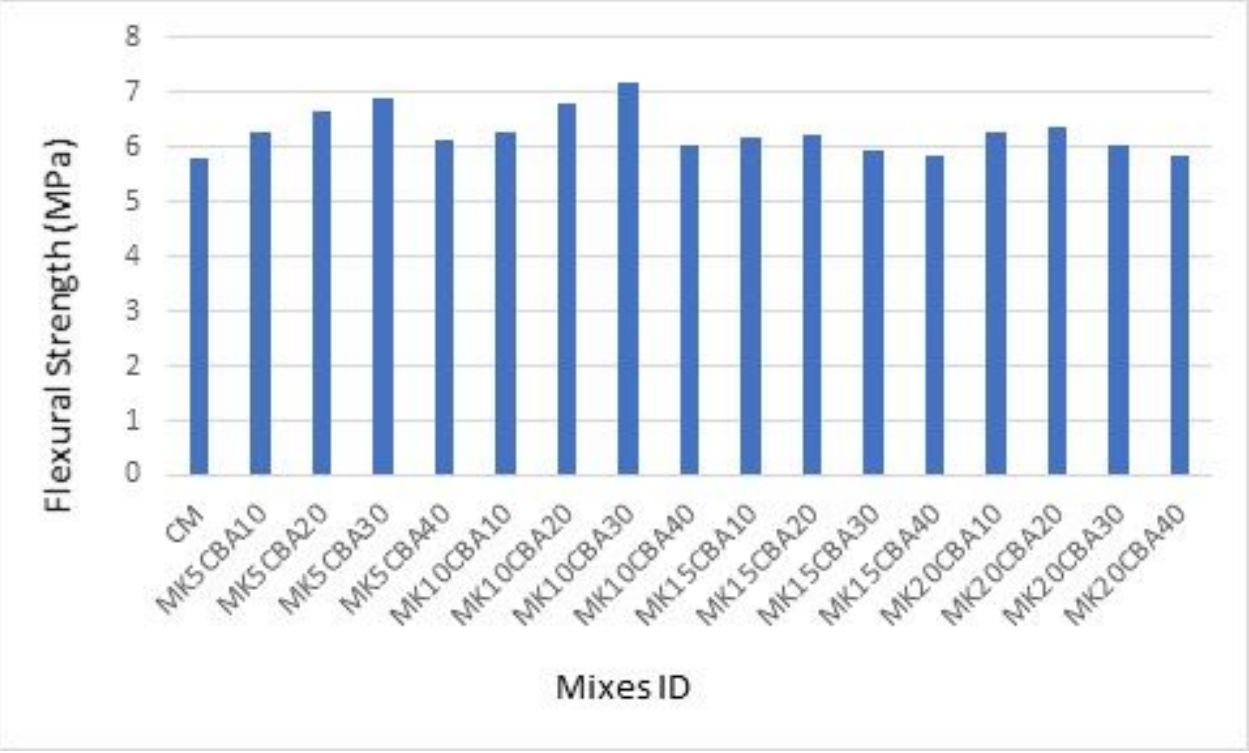

Figure 10

Flexural strength of CBA MK SCC at 28 days 


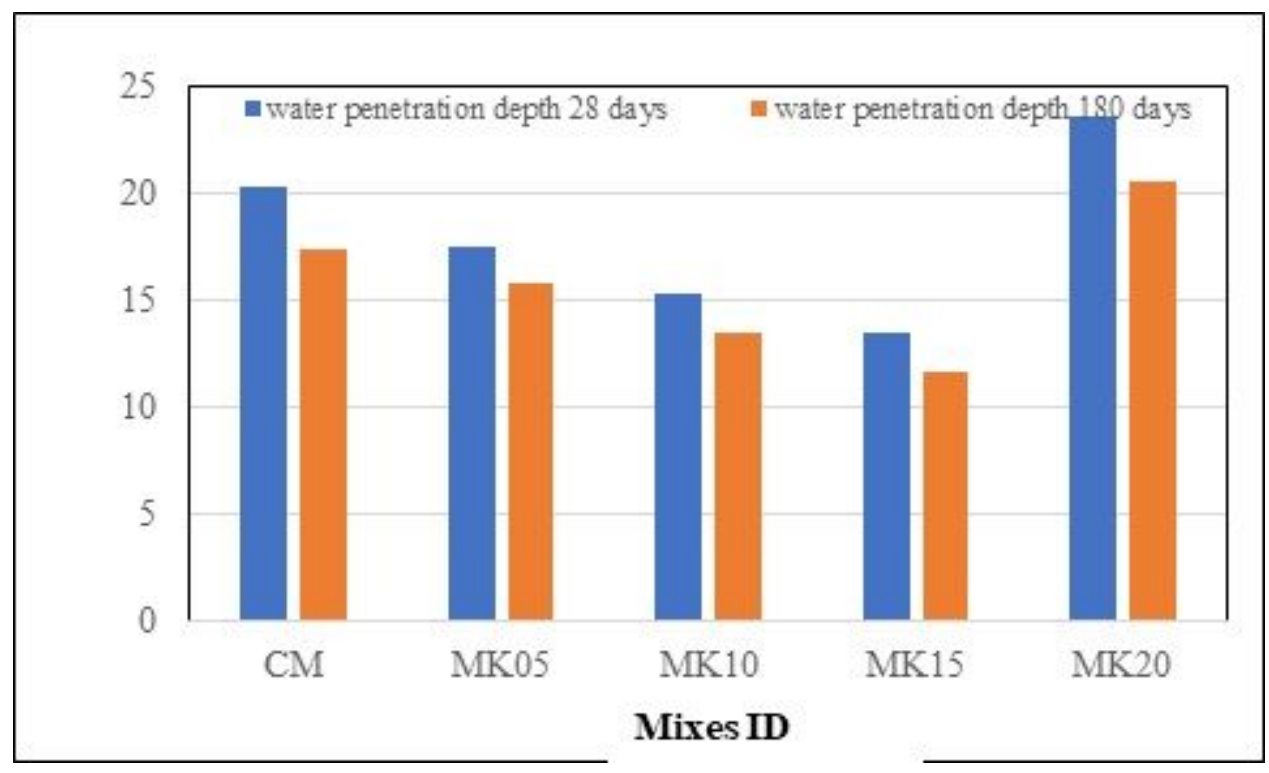

\section{Figure 11}

Water Penetration Depth of MK SCC at 28 and 180 days

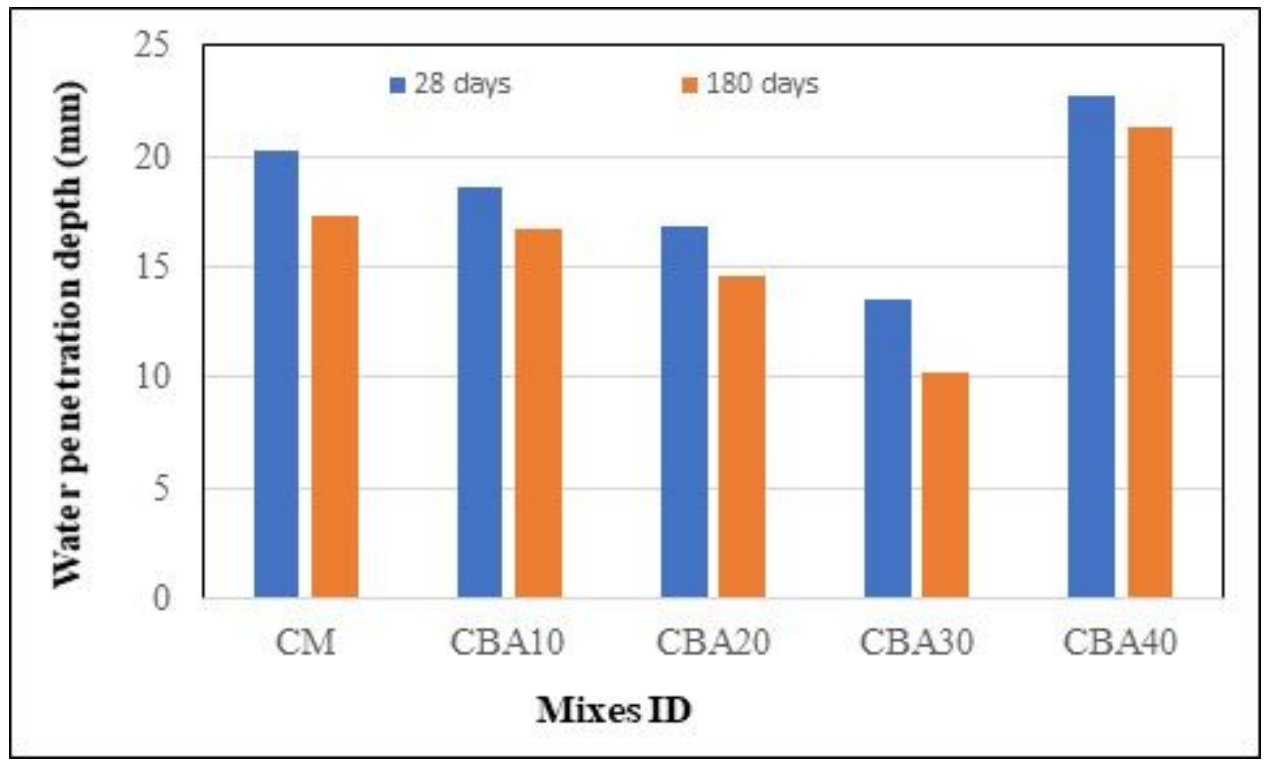

Figure 12

Water Penetration Depth of CBA SCC at 28 and 180 days 


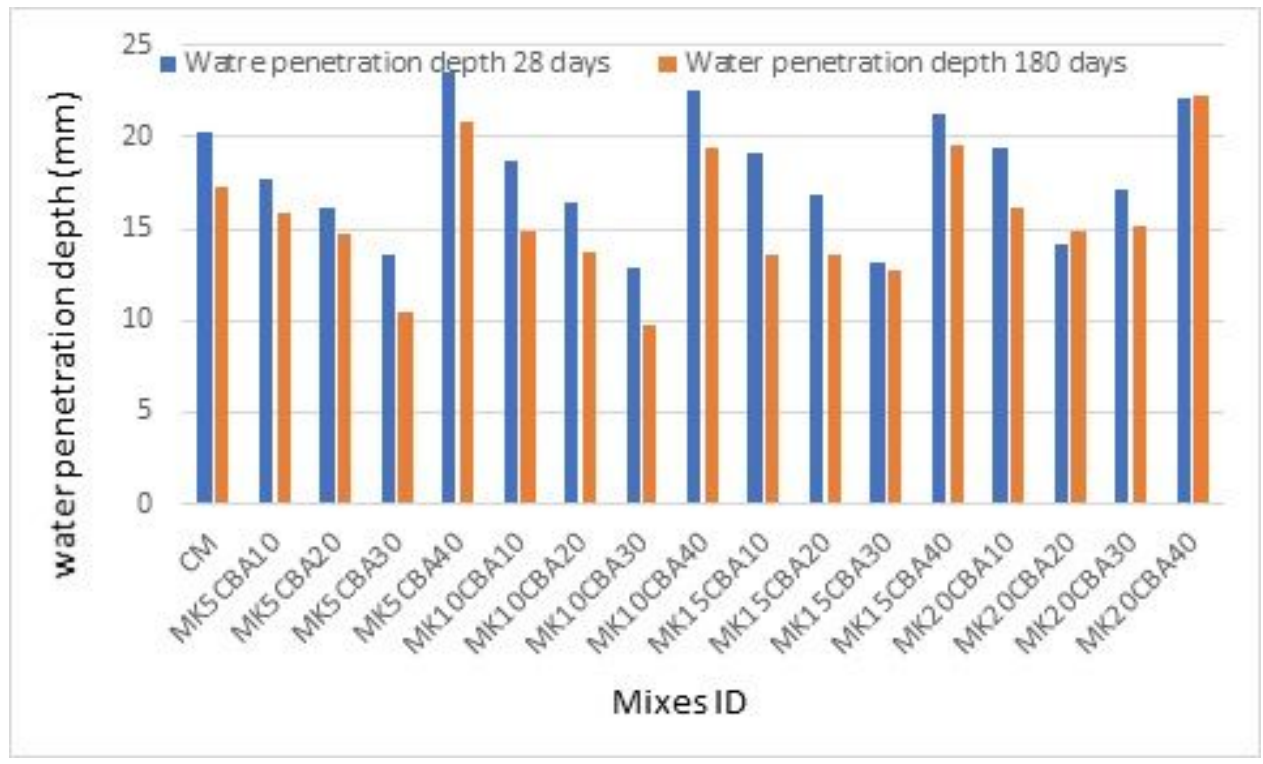

Figure 13

Water Penetration Depth of MKCBA SCC at 28 and 180 days

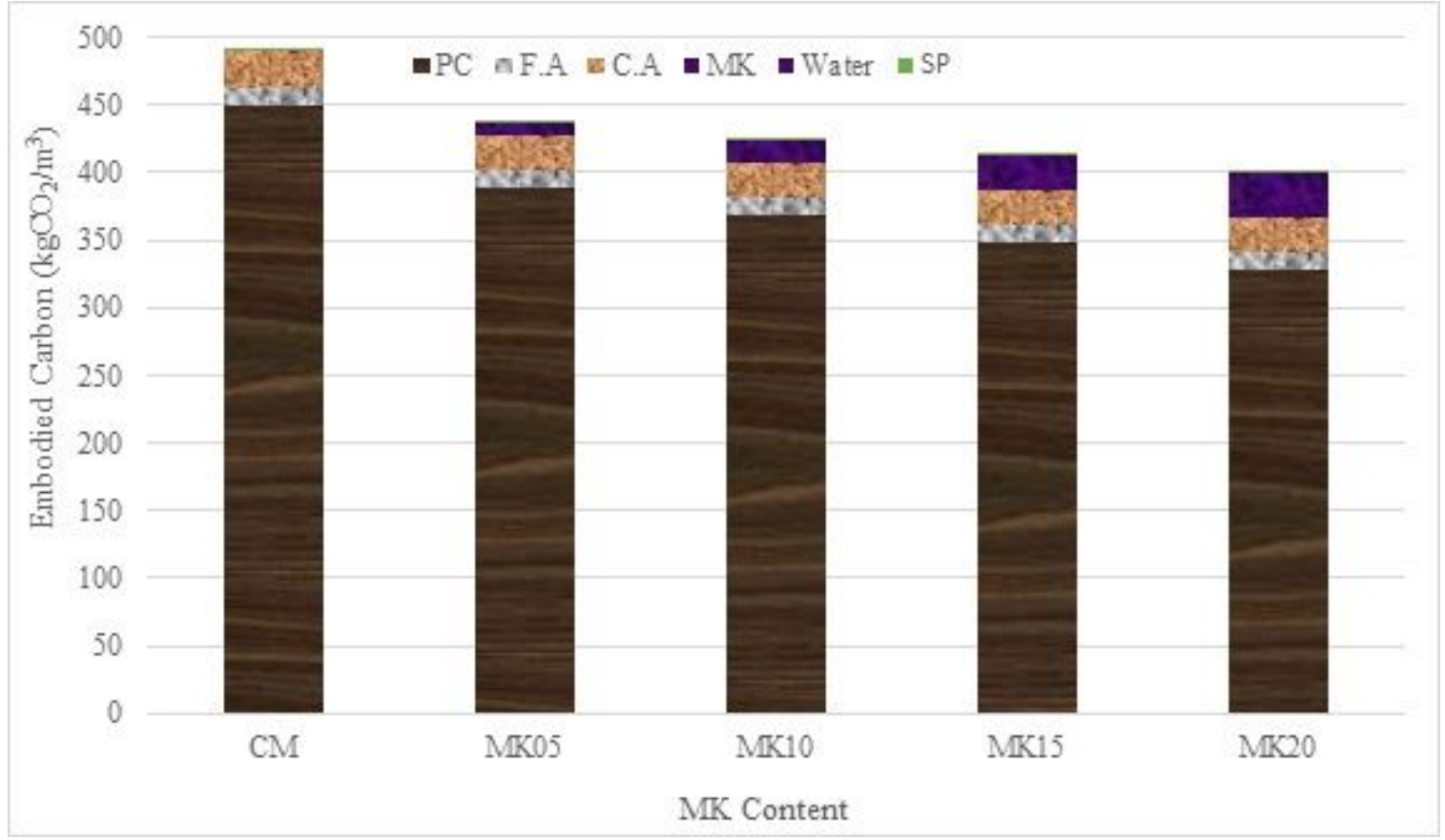

Figure 14

Embodied Carbon of Concrete including MK 


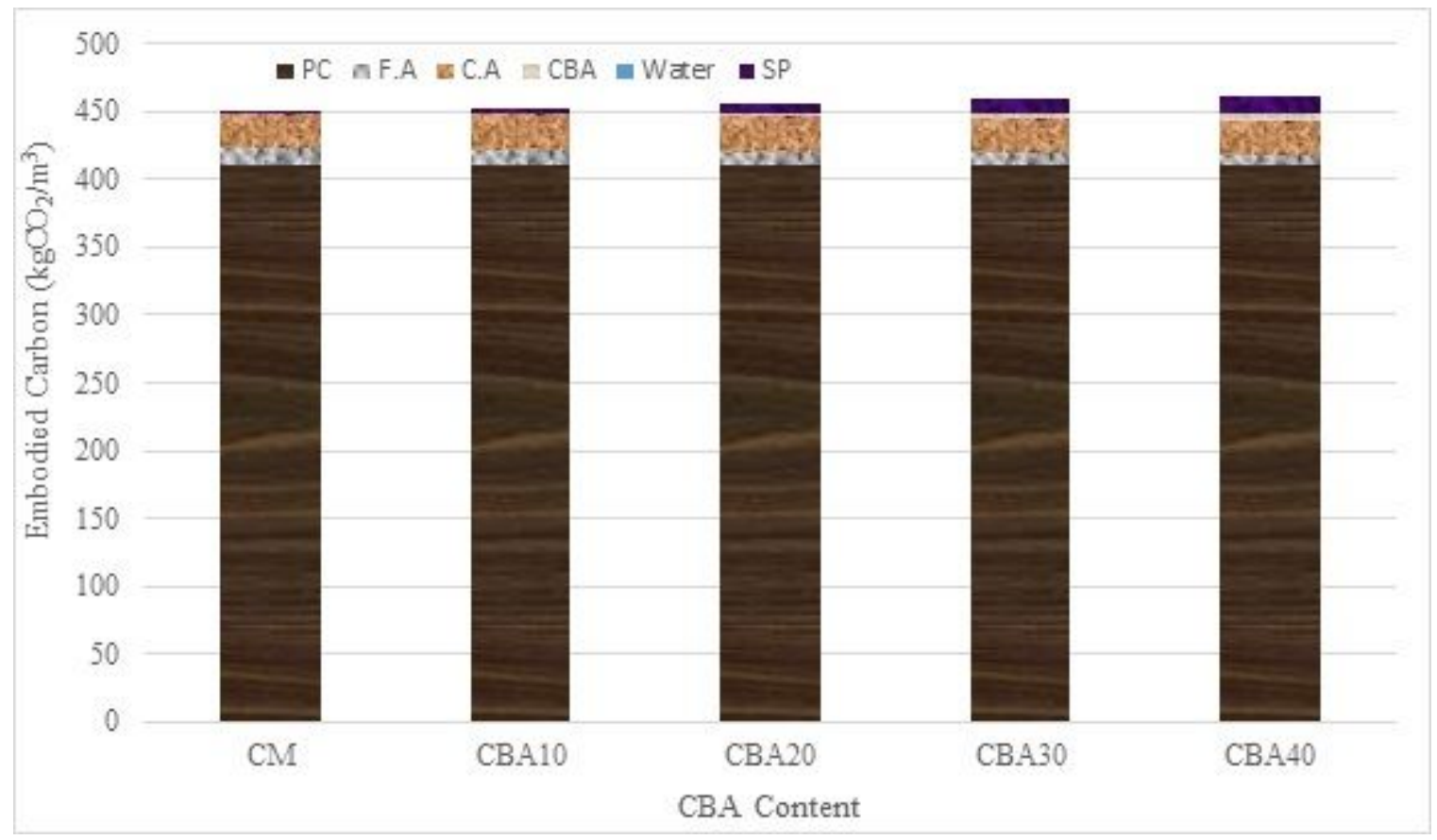

Figure 15

Embodied Carbon of Concrete containing CBA

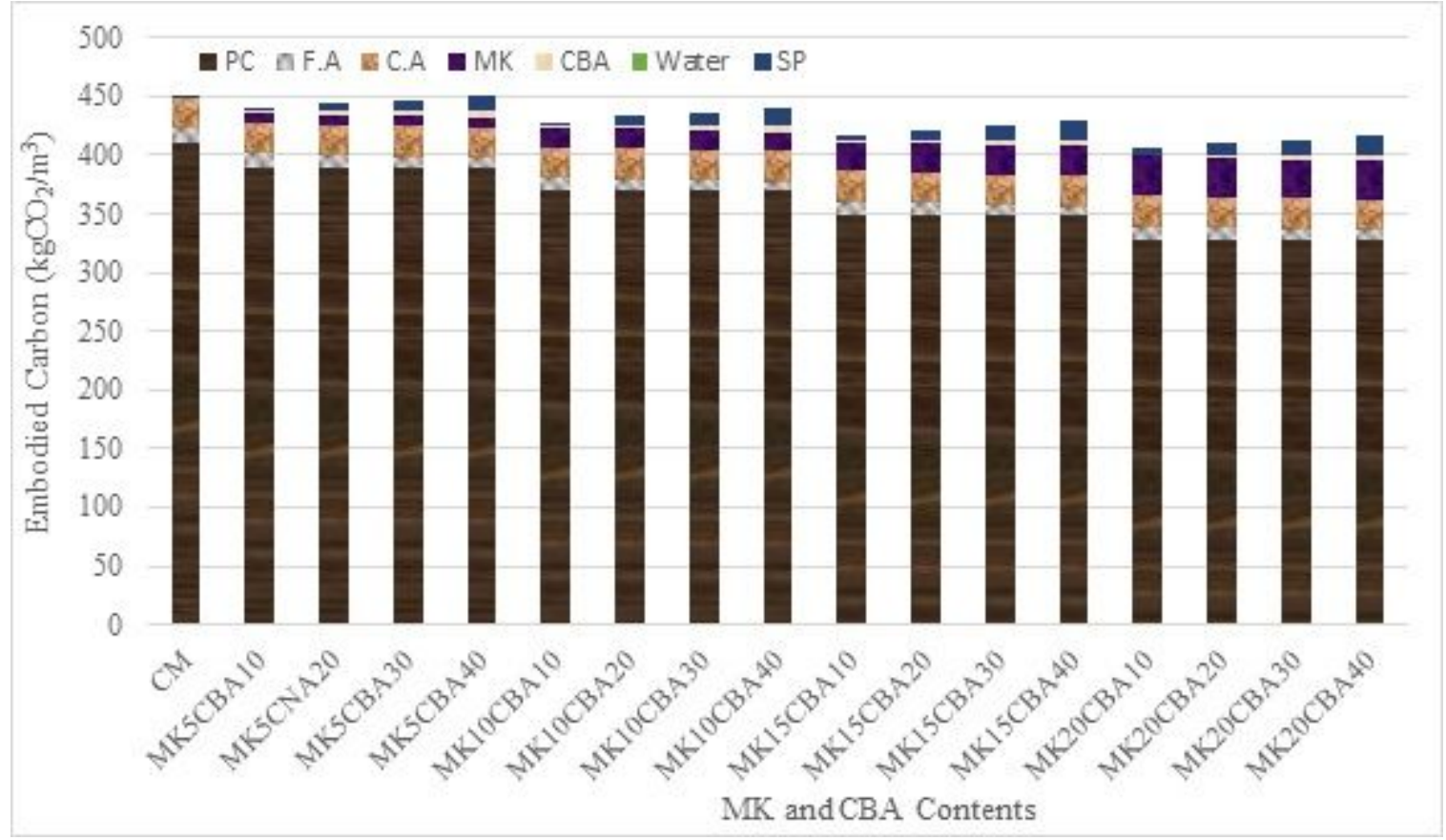

Figure 16

Embodied Carbon of Concrete including MK and CBA 